\title{
Pulmonary Imaging Findings in Coronavirus Disease 2019 (COVID-19): A Series of 140 Latin American Children
}

Carlos Ugas-Charcape ( $\square$ cugas@insnsb.gob.pe)

Instituto Nacional de Salud del Niño San Borja https://orcid.org/0000-0002-8380-3276

María Elena Ucar

Hospital de Niños Sor María Ludovica

Judith Almanza-Aranda

Salud Digna https://orcid.org/0000-0002-2146-9356

\section{Emiliana Rizo-Patrón}

Instituto Nacional de Salud del Niño San Borja https://orcid.org/0000-0002-2555-3774

Claudia Lazarte Rantes

Instituto Nacional de Salud del Niño San Borja https://orcid.org/0000-0002-4401-1129

\section{Pablo Caro-Domínguez}

Hospital Universitario Virgen del Rocío https://orcid.org/0000-0003-3540-6580

\section{Lina Cadavid}

Hospital Pablo Tobón Uribe https://orcid.org/0000-0002-3376-9911

\section{Lizbet Pérez-Marrero}

Clínica Alemana de Santiago https://orcid.org/0000-0002-1275-0840

\section{Tatiana Fazecas}

Hospital Municipal Jesus https://orcid.org/0000-0002-8747-4211

\section{Lucía Gómez}

Hospital Pediátrico Baca Ortiz

\section{Mariana Sánchez Curiel}

Hospital Infantil de México Federico Gómez

\section{Walter Pacheco}

Hospital María Especialidades Pediátricas

\section{Ana Rizzi}

Hospital de Pediatría Prof. Dr. Juan P. Garrahan

\section{Andrés García-Bayce}

Centro Hospitalario Pereira Rossell

\section{Efigenia Bendeck}

Hospital Nacional de Niños "Benjamín Bloom"

\section{Walter Montaño}


Hospital Santa Cruz CPSD

\section{Pedro Daltro}

Alta Excelência Diagnóstica https://orcid.org/0000-0001-7279-5680

José D. Arce V

Clínica Santa María de Santiago

\section{Research Article}

Keywords: SARS-CoV-2, COVID-19, children, pulmonary imaging, chest x-ray

Posted Date: October 20th, 2020

DOI: https://doi.org/10.21203/rs.3.rs-94820/v1

License: (c) (1) This work is licensed under a Creative Commons Attribution 4.0 International License. Read Full License

Version of Record: A version of this preprint was published at Pediatric Radiology on April 1st, 2021. See the published version at https://doi.org/10.1007/s00247-021-05055-2. 


\section{PULMONARY IMAGING FINDINGS IN CORONAVIRUS DISEASE 2019 (COVID-19): A SERIES OF 140 LATIN AMERICAN CHILDREN}

Authors:

Carlos F. Ugas-Charcape ${ }^{1}$, María Elena Ucar², Judith Almanza-Aranda3, Emiliana Rizo-Patrón", Claudia Lazarte Rantes ${ }^{1}$, Pablo Caro-Domínguez ${ }^{5}$, Lina Cadavid ${ }^{6}$, Lizbet Perez ${ }^{7}$, Tatiana Fazecas ${ }^{8}$, Lucía Gomez ${ }^{9}$, Mariana Sanchez ${ }^{10}$, Walter Pacheco ${ }^{11}$, Ana Rizzi ${ }^{12}$, Andrés García-Bayce ${ }^{13}$, Efigenia Bendeck $^{14}$, Mario Montaño ${ }^{15}$, Pedro Daltro ${ }^{16}$, José D Arce-V17

\section{Affiliations:}

1. Department of Diagnostic Imaging. Instituto Nacional de Salud del Niño San Borja. Av. Javier Prado Este 3101, Zip code 15037. Lima, Perú.

2. Servicio de Diagnóstico por Imágenes. Hospital de Niños Sor María Ludovica, Calle 14 N" 1631. Zip code 1900. La Plata, Argentina.

3. Servicio de Imagenología, Salud Digna. Av. Universidad 1338, Del Carmen, Coyoacán, 04100. Ciudad de México, México.

4. Unidad de Desarrollo de Investigación, Tecnologías y Docencia. Instituto Nacional de Salud del Niño San Borja. Av. Javier Prado Este 3101, Zip code 15037. Lima, Perú.

5. Unidad de Radiología Pediátrica, Servicio de Radiología, Hospital Universitario Virgen del Rocío. Av. Manuel Siurot, S/n, 41013 Sevilla, España.

6. Radiology Department. Hospital Pablo Tobón Uribe - IMEDI. Calle 78b \#69 - 240, Zip code 050034. Medellín, Colombia.

7. Imaging Department. Clínica Alemana de Santiago. Santiago, Chile

8. Serviço de Imagem do Hospital Municipal Jesus. DASA. Rio de Janeiro, Brasil.

9. Servicio de Imagen. Servicio de Hospital Pediátrico Baca Ortiz. Quito, Ecuador.

10. Imaging Department, Hospital Infantil de México Federico Gómez. Ciudad de México, México.

11. Servicio de radiología e imágenes médicas. Hospital María Especialidades Pediátricas. Tegucigalpa Honduras 
12. Departamento de Diagnóstico por Imágenes. Hospital de Pediatria JP Garrahan. Buenos Aires, Argentina

13. Department of Imaging. Centro Hospitalario Pereira Rossell. Montevideo, Uruguay

14. Departamento de radiología e imágenes. Hospital Nacional de Niños "Benjamín Bloom”. San Salvador, El Salvador.

15. Servicio de Diagnóstico por Imágenes. Hospital Santa Cruz CPSD. Santa Cruz de la Sierra, Bolivia.

16. Alta Excelência Diagnóstica / DASA and Clínica de Diagnóstico por Imagem / DASA. Rio De Janeiro, Brasil.

17. Servicio de Radiología e Imágenes. Clínica Santa María. Av. Santa María 0500, Providencia. Zip code: 7500000. Santiago, Chile.

\section{Author disclosures:}

All authors have nothing to disclose.

\section{Corresponding author:}

cugas@insnsb.gob.pe 


\section{Abstract \\ Background:}

The severe acute respiratory syndrome coronavirus 2 (SARS-CoV-2 virus), which resulted in the worldwide COVID-19 pandemic of 2020, has particularly affected Latin America.

\section{Objective:}

The purpose of the study was to analyze the imaging findings of pulmonary COVID-19 in a large pediatric series.

\section{Materials and methods:}

Children with confirmed SARS-CoV-2 infection confirmed by either quantitative reverse transcription-polymerase chain reaction from nasopharyngeal swabs or presence of circulating IgM and/or IgG antibodies and who underwent chest radiograph (CXR) and/or computed tomography (CT) were included in this retrospective multicenter study. Three pediatric radiologists independently reviewed CXRs and CTs to identify the presence, localization, distribution and extension of pulmonary lesions.

\section{Results:}

One hundred and forty children (71 female; median age 6.2 years; interquartile range 1.6-12.1 years) were included in the study. Peribronchial thickening (93\%), ground glass opacities (79\%) and vascular engorgement (63\%) were the most frequent findings on 131 CXRs. Ground glass opacities (91\%), vascular engorgement (84\%) and peribronchial thickening (72\%) were the most frequent findings on 32 CTs. Peribronchial thickening (100\%), ground-glass opacities (90\%) and pulmonary vascular engorgement (74\%) were common CXR findings in asymptomatic patients $(n=20)$. Consolidation and ground-glass opacity were significantly higher in patients who needed ICU admission or expired, in contrast with patients with a good outcome $(48 \%$ and $91 \%$, vs $24 \%$ and $70 \%$ p $<0.05$, respectively).

\section{Conclusion:}


Asymptomatic children and those with mild symptoms of COVID-19 showed mainly peribronchial thickening, ground-glass opacities and pulmonary vascular engorgement on CXRs. Ground glass opacity and consolidation, were more common in patients who required ICU admission or died.

Key words: SARS-CoV-2, COVID-19, children, pulmonary imaging, chest x-ray. 


\section{Introduction}

Severe acute respiratory syndrome coronavirus 2 (SARS-CoV-2), which causes coronavirus disease 2019 (COVID-19), represents an ongoing and enduring worldwide health threat [1]. Since the first reported case of COVID-19 reported in Brazil in late February 2020, the infection rate in Latin America has increased exponentially, with more than 9 million cases and over 330,000 official deaths to date [2].

Although COVID-19 predominantly affects the adult population, children and young adults are not exempt from infection, and they can further increase community transmission rates [3]. Despite their higher probability of experiencing only a mild clinical course; some severe cases have been reported, including children with multifocal pneumonia that progresses to respiratory failure and multisystem immune-mediated inflammatory disease called "multisystem inflammatory syndrome in children" (MIS-C) [4,5].

The first imaging studies of patients with COVID-19 included a small number of cases and were not exclusively pediatric [6,7]. The initial large pediatric series of cases showed that chest radiographs (CXR) and computed tomography (CT) findings in COVID-19 are nonspecific and they are not helpful in differentiating this infection from other childhood lower respiratory tract infections or pneumonia $[8,9]$.

The current study is the first international multicenter investigation promoted by the Latin American Society of Pediatric Radiology (SLARP), and its aim is to report on radiologic pulmonary findings in a large pediatric series.

\section{Material and Methods}

The Ethics Committees and institutional review boards (IRB) of the Instituto Nacional de Salud del Niño San Borja (Lima, Perú), the Hospital Infantil de México Federico Gómez (Mexico City, Mexico) and the Hospital de Niños Sor María Ludovica (La Plata, Argentina) approved the study. 
The institutions in Perú and Mexico waived the requirement for informed patient consent, and written informed consent was obtained at the hospital in Argentina. Members of the SLARP from all Latin American countries were invited to participate.

\section{Patients}

The study included consecutive pediatric patients (aged 18 and younger) with COVID-19 infection as confirmed by real-time reverse-transcriptase polymerase chain reaction (RT-PCR) or immunoglobulin M (IgM) or immunoglobulin G (IgG) serology who underwent at least one thoracic imaging modality (CXR or CT) between May 15th and June 25th, 2020. We retrospectively reviewed clinical data, including demographics, symptoms, days from symptom onset to exam date, comorbidities, Intensive Care Unit (ICU) admission, and fatal outcomes. A standardized data collection spreadsheet was used by collaborators to record the clinical data from each site

Image Acquisition

CXR and CT images were acquired in accordance with institutional protocols of each participating center. The choice of imaging technique depended on equipment availability and clinical context, as well as regional/national needs and recommendations. Images were anonymized, coded and stored in an online digital repository for assessment.

\section{Imaging interpretation}

Three pediatric radiologists (M.E.U., P.D. and J.A.V.), with 24, 35 and 43 years of experience in pediatric radiology, respectively, independently reviewed the images using an electronic data capture form using a free DICOM software viewer (RadiAnt ${ }^{\mathrm{TM}}$, Medixant, Maciej Frankiewicz, Poznan, Poland). Despite awareness that all subjects had tested positive for infection with the SARS-CoV-2 virus, the reviewers were blinded to clinical and outcome information. CXRs and CT images were analyzed to identify the presence of pathologic findings such as peribronchial thickening, ground-glass opacities, crazy-paving opacities, consolidations, halo signs, reversed 
halo signs, and other abnormalities. The definitions for the findings were adapted from the Fleischner Society's Glossary of Terms for Thoracic Imaging [10]. The radiologists assessed the presence, localization, distribution, and extension (number of lobes involved) of the pulmonary lesions.

CXR vascular engorgement was defined as positive when pulmonary vessels were found up to the subpleural level (especially in the longitudinal vessel plane) and when their diameter was greater than the accompanying bronchus (in the axial vessel plane). Due to the high frequency of vascular engorgement, a separate analysis was carried out by the three pediatric radiologists to determine the presence of vascular engorgement as the a predominant pattern in CXRs. Patients with comorbidities such as congenital heart disease and other pulmonary overflow-causing pathologies that could confound this sign were excluded.

Statistical analysis

To define the presence of a pathologic finding, its localization and distribution, the agreement of at least two reviewers was required. We determined inter-rater agreement between all three evaluators for four CXR signs (peribronchial thickening, ground-glass opacity, vascular engorgement and consolidation) and eight tomographic signs (peribronchialthickening, ground glass opacity, consolidation, crazy paving, halo signs, reverse halo signs, vascular engorgement and linear opacities) using Fleiss's Kappa statistic or Brennan-Prediger's Kappa coefficient in the presence of high agreement, low Kappa paradox [11,12]

Continuous variables were expressed as medians and interquartile ranges or means and standard deviation, categoric variables were presented as values and percentages. Relative frequencies were calculated on valid results, excluding missing values. The frequencies of pathologic findings were calculated for each clinical characteristic and were compared by chi-square or Fisher exact tests. The number of days from onset of symptoms until the image date for each finding was compared using the Mann-Whitney U test. Two-tailed $\mathrm{p}<0.05$ was considered statistically 
significant. All statistical analyses were performed with Stata 15 software (StataCorp. 2017. Stata Statistical Software: Release 15. College Station, TX, USA: StataCorp LLC).

\section{Results}

Patients and clinical findings

The final study population included 140 children, after excluding 8 subjects because of the nondiagnostic quality of images. Participants included 69 males and 71 females, with a median age of 6.2 years, and an interquartile range of 1.6-12.1 years. All participants had COVID-19 infection confirmed by RT-PCR ( $\mathrm{n}=126,90 \%)$ or immunoglobulin (IgG and IgM) tests ( $\mathrm{n}=14,10 \%)$ were included. One hundred and thirty-one patients had CXR (108 had only CXR), and 32 patients had CT ( 9 had only CT). Table 1 summarizes the demographic, clinical, and radiological findings. For analytical purposes, the participants were divided into three groups: the preschool age group included participants 0 to 6 years old $(47.1 \%)$, the primary school age group included participants 6 to 13 years old (30.0\%), and the teenaged group included participants 13 to 18 years old $(22.9 \%)$.

Cases were submitted from Peru $(n=47,33.6 \%)$, Mexico $(n=26,18.6 \%)$, Brazil $(n=16,11.4 \%)$, Argentina $(n=15,10.7 \%)$, Colombia $(n=12,8.6 \%)$, Ecuador $(n=11,7.9 \%)$, Honduras $(n=8,5.7 \%)$, Chile (n=3, 2.1\%) and El Salvador ( $\mathrm{n}=2,1.4 \%)$.

The majority of participants were experiencing symptoms at the time of imaging $(n=117,85.4 \%)$, with fever the most common in $60.5 \%(n=83)$ participants, followed by dyspnea $(n=39,28.4 \%)$ and cough $(\mathrm{n}=27,19.7 \%)$. Indications for imaging included the assessment of SARS-CoV-2 infection in 58 participants (42.6\%), diagnosis of lower respiratory tract infection in 37 participants (27.2\%), evaluation of previous established comorbidities or acute disease in 31 participants (22.8\%), and detection of possible complications in 10 participants (7.4\%). In four participants the imaging indication was not specified. 
Approximately two-thirds of the patients $(65.7 \%, \mathrm{n}=92)$ had underlying conditions at the time of diagnosis of SARS-CoV-2 infection. Sixteen patients had congenital heart disease (11.5\%), 13 had cancer (9.3\%), and 10 had an immunodeficiency disorder (7.2\%). Other underlying conditions of various etiologies were documented in the remaining 53 patients (Online Supplemental Material 1, Table 1).

Of all participants, $62.5 \%(\mathrm{n}=85)$ had a good clinical course and were discharged after improvement; and $28.7 \%(n=39)$ were admitted to the ICU or underwent mechanical ventilation. Twelve participants $(8.8 \%)$ died despite resuscitation measures. We were unable to obtain clinical follow-up data for four participants.

\section{Chest radiography}

All of the analyzed 131 CXRs had positive findings (summarized in Table 2). CXR were acquired on average $2.3 \pm 2.3$ days after the onset of symptoms. The most frequent finding was peribronchial thickening in $93.1 \%(n=122)$ (Fig. 1), followed by ground-glass opacity in $78.6 \%$ $(n=103)$ and vascular engorgement in $62.6 \%(n=82)$.

Ground-glass opacities were described as predominantly bilateral $(n=65 ; 79.3 \%)$, peripheral $(\mathrm{n}=45 ; 52.9 \%)$, and in the lower lobes ( $\mathrm{n}=48 ; 51.1 \%)$ (Fig. 2 and Fig. 3). Vascular engorgement was bilateral in most cases $(\mathrm{n}=59 ; 90.8 \%)$ and was generalized, in both upper and lower lobes (n=44; 57.1\%) (Fig. 4, Fig. 5 and Fig. 6). Consolidation was found in $32.8 \%$ of CXR (n=43), most frequently peripheral $(n=11 ; 78.6 \%)$, unilateral $(n=21 ; 60 \%)$ and affecting the lower lobes $(n=27$; 64.3\%) (Fig. 7). Other findings are noted in table 1.

The frequency of ground-glass opacity was higher in the preschool age group ( $n=56 ; 88.9 \%)$ and lower in the teenaged group $(n=20 ; 66.7 \%, p=0.017)$. Vascular engorgement was observed more frequently in primary school children than in the preschool age and teenaged groups $(79 \%$ vs. $54 \%$ and $60 \%, \mathrm{p}=0.036$ ). Consolidation was more frequent in teenagers and less frequent in preschoolers (53.3\% vs. 23.8\%, p<0.019) (Table 3). 
Compared with asymptomatic patients, consolidation was found more frequently in symptomatic patients $(36.7 \%$ vs. $10.5 \%, \mathrm{p}=0.032)$. Findings like peribronchial thickening (100\%), ground-glass opacity (89.5\%) and vascular engorgement (73.7\%) were more frequent in asymptomatic patients; however, no statistical significance was found (Table 3).

In participants with a good clinical course who were not admitted to the ICU, peribronchial thickening was the most frequent imaging finding (97.5\%), followed by ground-glass opacity (70.4\%), vascular engorgement (69.1\%) and consolidation (23.5\%) (Table 3). CXR of patients with a more severe clinical course (ICU admission, mechanical ventilation or death), showed ground glass opacity in $91.3 \%$, peribronchial thickening in $84.7 \%$, followed by vascular engorgement and consolidation with $47.8 \%$ each (Table 3 ). Therefore, CXR findings correlated to clinical course: peribronchial thickening and vascular engorgement were frequent findings in participants with good outcomes than in those who required ICU admission or expired ( $p=0.011$ and 0.015 respectively). Consolidation and ground-glass opacity were more frequently found in participants who required ICU admission or died than in those who had a milder clinical course ( $p=0.006$ and $p=0.007$, respectively).

The median number of days from onset of symptoms until the CXR was greater for participants with consolidation than for participants with no consolidation (two days vs. one day, $p=0.0279$ ). Consolidation was found in $29.4 \%$ of CXRs taken less than 7 days from clinical onset compared to $61.1 \%$ in radiographs taken more than 7 days from clinical onset $(\mathrm{p}=0.010)$. No statistically significant association was found between the time from the onset of symptoms and other radiological signs (Table 3 and Online Supplemental Material 2, Fig. 1).

After excluding underlying cardiovascular disease and other conditions related to pulmonary vascular overflow, vascular engorgement was the predominant pattern in 25 participants (21.9\%) (Fig. 5 and fig. 6). The pattern was most frequent in male patients (60\%), in the primary school group (44\%) and in symptomatic participants (83.3\%). It was present in $16.7 \%$ of asymptomatic participants. Patients who were imaged < seven days after symptom onset showed 
vascular engorgement on the chest radiograph in $91.2 \%$ of cases. For four children with vascular engorgement on initial CXR, the progression to ground glass opacity or consolidation was confirmed in follow-up CXR or CT (Fig. 7).

\section{Chest CT}

Chest CT was performed in 32 children in our cohort, on average $8.8 \pm 10.1$ days after the onset of symptoms. The most frequent CT findings were ground-glass opacity $(90.6 \%, \mathrm{n}=29)$ and vascular engorgement $(84.4 \%, \mathrm{n}=27)$. Ground glass opacity was characteristically bilateral (79.3\%), diffuse (76\%), and with segmental (48\%) and subpleural distributions (45\%) (fig. 8). Regarding CT findings by age group, ground-glass opacity was present in $100 \%$ preschoolers, in $90.9 \%$ of the primary school group, and in $83.3 \%$ of the teenagers. Vascular engorgement was found characteristically in the lower lobes (100\%) and bilaterally (84\%).

Central peribronchial thickening was found in $71.9 \%$ of the CTs ( $n=23$ ) (Fig. 9). Consolidation was identified in $68.8 \%$ of CT images $(n=22)$, affecting two pulmonary lobes on average. Halo signs, reverse halo signs, and crazy paving were present in $37.5 \%, 34.4 \%$ and $31.3 \%$ of CTs, respectively (Fig. 8). Consolidation, halo signs, reverse halo signs, and crazy paving were more frequent in teenagers, representing $75 \%, 50 \%, 50 \%$ and $41 \%$ respectively.

\section{Interobserver agreement}

All agreement measures (Kappa statistic) for the four radiological signs and eight tomographic signs ranged between 0.13 and $0.58(p<0.05)$ indicating slight to moderate agreement [11] among all reviewers. The sign with the poorest observed agreement was CXR vascular engorgement (58.9\%); peribronchial thickening showed the greatest agreement (88.8\%). (Table 4)

\section{Discussion}

CXR is the recommended initial modality to evaluate the pulmonary effects of COVID-19 infection in children, and our study revealed that all radiographs of proven COVID-19-infected child 
participants were abnormal. The first published studies of children $[13,14]$ reported few findings in CXRs; however, subsequent reports [9] highlighted findings that had probably not been considered, such as peribronchial thickening. It is known that intra and interobserver variability account for differences due to varying observer expertise in the imaging interpretation of pediatric pneumonia [15]. In our cohort, peribronchial thickening was the most frequent finding in CXRs, consistent with the study conducted by Caro-Dominguez et al. [9]. This finding reflects airway involvement secondary to infection due to the SARS-CoV-2 virus and airway inflammation. The anatomical characteristics of the tracheobronchial tree in children, with shorter and narrower airway branches, promote greater small particle and microorganism deposition in the respiratory tract, especially in the upper airways, compared to adults [16]. Many other viruses and inflammatory diseases besides COVID-19 lead to central peribronchial thickening; therefore, this is a nonspecific radiological sign of limited diagnostic value. The feature was present in all age groups, and was also identified by CT (72\%). Chen et al [6] reported that CT bronchial wall thickening was more commonly seen in children than in adults.

The SARS-CoV-2 virus infects the host by binding its surface protein $S$ to angiotensin converting enzyme 2 (ACE-2) receptors in alveolar cells, and also in cells of the intestine, kidney, heart and vascular endothelium [17]. In the parenchymal lung, COVID-19 causes alveolar epithelium damage, and variable degrees of exudation into the air space, which is manifested as ground-glass opacity, consolidation, or crazy paving. In our case series, ground-glass opacity was the second most frequent finding in CXRs and the most frequent feature on CT (91\%). The most common ground glass-opacity distribution was bilateral and peripheral, with lower lobe predominance, which is in agreement with previously published studies [18-20]. Ground-glass opacity was most common in children younger than six years old $(88.9 \%, \mathrm{p}<0.05)$. This pattern was also most frequent during the first week of SARS-CoV-2 infection and was associated with an unfavorable disease course. 
Consolidation was most frequently seen in teenagers $(53 \%, \mathrm{p}<0.05)$, with unilateral and peripheral distribution. However, it was also identified in asymptomatic children (10\%), and increased in frequency and extension after seven days of known COVID-19 and in patients with unfavorable course.

Our study has demonstrated that imaging of asymptomatic children can show findings of active infectious disease. In our cohort, $14 \%$ of children who were asymptomatic but produced positive RT-PCR tests had peribronchial thickening, and many had ground-glass opacity and pulmonary vascular engorgement. Consolidation was found significantly less frequently in this group than in symptomatic children.

In our study, 32 children were evaluated with chest $\mathrm{CT}$, most at seven days after clinical onset. The main finding was ground-glass opacity, in agreement with previously published data [21-27]. In contrast with our findings, some authors, also based on pediatric CT findings, reported more localized ground-glass opacity, lower ground-glass attenuation, and lower lobar involvement in pediatric studies [24]. Some of our cases were associated with uncharacteristic imaging patterns, such as pseudo-nodular ground-glass opacity or consolidation, opacities with the peribronchovascular bundles (bronchopneumonic pattern) or manifested as ill-defined groundglass nodules (Fig. 10). These imaging features may be less common findings or represent early stages of pulmonary compromise in SARS-CoV-2 infection, previous to consolidation. Nevertheless, we could not rule out concurrent bacterial or viral infections.

In many studies $[8,9,19]$, ground-glass opacity has been associated with consolidation areas, halo signs or reverse halo signs. These findings were also present in our participants, mainly in teenagers. In contrast with Xia et al. [8], who suggested that the halo sign might be considered a typical sign in pediatric patients with COVID-19, we did not identify significant statistical data to assert this hypothesis. 
During CXRs evaluation, we found dilatation of the peripheral pulmonary vessels in nearly $63 \%$ of our cases. Some recently published studies have reported vascular engorgement in COVID-19, almost all were focused on adult chest CT findings [28-30]; in agreement with these reports, in our CT series we found this feature in $84 \%$ of cases in our CT studies. To the best of our knowledge, this finding has not been previously reported in CXRs of pediatric patients. To further study the features of this finding, the evaluators excluded all participants with congenital heart disease or other comorbid conditions that might cause pulmonary overflow and mild vascular dilatation. Also, it should be mentioned that none of the submitted cases had myocarditis or MISC. The evaluator consensus resulted in 25 patients with vascular engorgement as the predominant CXR pattern. In this group of participants, the feature was seen predominantly in the lower lobes, had a bilateral distribution, and was identified as isolated or in association with perihilar peribronchial wall thickening. Nevertheless, this finding had the poorest agreement among our evaluators, and in addition, this finding may be a challenge to be identified by radiologists with little experience in evaluating pediatric chest imaging studies.

Despite widespread interest in the pathophysiology of SARS-CoV-2 infection, there is little published evidence regarding changes in peripheral lung vessels in pediatric patients. Recently, Lang et al. [29] suggested that abnormal pulmonary vasoregulation could play an important role in COVID-19, and concluded that the dilatation of medium to small vessels, including subpleural vessels, may occur throughout the lung (not only in compromised areas), which could indicate a diffuse vascular process. Using a parallel rationale, we suggest that the pulmonary vascular engorgement found in initial CXRs reflects changes in lung parenchymal vasculature at an early stage of COVID-19 in children (Fig. 4, Fig. 5, Fig. 6 and Fig. 7).

Some post-mortem studies have highlighted the disease-related vascular changes as a distinctive feature of SARS-CoV-2 infection [31]. Damage to the vascular endothelium has been described, 
and also associated with the intracellular presence of the virus, distal thrombi in small pulmonary vessels, and angiogenesis [17,31]. Cavagna et al. [32], argued that hypercoagulability associated with SARS-CoV-2 infection and concomitant endothelial damage may have an important role in pulmonary vessel damage and thrombosis. Nevertheless, validation studies are needed to thoroughly corroborate the pulmonary vascular changes and damage in children with COVID-19.

Besides the absence of normal vessel tapering toward the lung periphery, in some CTs we also noticed small dilated vessels running parallel to the pleural surface, with a "comb" appearance, (similar to the sign described in some inflammatory bowel diseases or in mesenteric vasculitis) $[32,34]$. We termed this finding as "pulmonary comb sign" (Fig. 11). Subpleural interlobular septal thickening is probably related to damage and engorgement of small peripheral venous vessels, and their involvement may cause pleural thickening and a small amount of pleural effusion, as observed in some of our participants. Some less common findings in our case series were pleural effusion, atelectasis, nodules and linear opacities. Lymphadenopathies were not observed.

Thoracic imaging findings certainly depend on the progress of COVID-19. It is well known initial chest CT is normal in approximately $40 \%$ of mild or asymptomatic COVID-19 cases [35,36]. In adult CTs, the most frequent finding is the ground-glass opacity, mainly in the second week of the disease $[25,26]$. In our cohort, a high number of cases showed a mixed pattern of ground-glass opacity, consolidation, pulmonary vascular dilatation and peribronchial thickening; probably because CT was performed only in very severe and advanced cases (more than seven days from symptom onset) and a high percentage of children had an underlying comorbidity $(65,7 \%)$. Socioeconomic factors should also be considered in Latin America, as later admissions into the health system are common. 
Our study has several limitations. First, it is a multicenter study with a heterogeneous data source and some incomplete clinical data. Second, different imaging acquisition protocols would impact the heterogeneous quality of the exams. Third, pediatric radiologists were not blinded to the COVID-19 diagnosis, so observer bias might be present. Despite these limitations, this study helps establish the radiological profile and evolution of COVID-19 in children.

\section{Conclusion}

Chest imaging findings in pediatric COVID-19 patients are nonspecific and cannot be distinguished from other pediatric airway infections, but some points can be learned from this study. Asymptomatic children and those with mild symptoms show mainly central peribronchial thickening, ground-glass opacities and vascular engorgement in chest radiography. In moderate and severe cases of the disease, chest radiography helps rule out complications and differential diagnoses, especially in children with underlying conditions. Ground-glass opacities are most frequently seen in younger children, while consolidation is most frequently observed in teenagers, who then have an unfavorable course. CT findings are nonspecific and this modality should be reserved for severe cases with unfavorable courses despite therapy. 


\section{References}

1. Palacios Cruz M, Santos E, Velázquez Cervantes MA, León Juárez M (2020) COVID-19, una emergencia de salud pública mundial. Revista Clínica Española. https://doi.org/10.1016/j.rce.2020.03.001

2. World Health Organization. WHO Coronavirus Disease (COVID-19) Dashboard. Data last updated: 2020/9/28, 3:52pm CEST. https://covid19.who.int/. Accessed September 28th, 2020.

3. Dong Y, Mo X, Hu Y, Qi X (2020) Epidemiological Characteristics of 2143 Pediatric Patients With 2019 Coronavirus Disease in China. Pediatrics; 145:e20200702. https://doi.org/10.1542/peds.2020-0702

4. Blumfield E, Levin TL (2020) COVID-19 in pediatric patients: a case series from the Bronx, NY. Pediatr Radiol; 50:1369-1374. https://doi.org/10.1007/s00247-020-04782-2

5. Levin M (2020) Childhood Multisystem Inflammatory Syndrome - A New Challenge in the Pandemic. N Engl J Med 2020; 383:393-395. DOI: 10.1056/NEJMe2023158

6. Chen A, Huang J, Liao Y, et al (2020) Differences in Clinical and Imaging Presentation of Pediatric Patients with COVID-19 in Comparison with Adults. Radiol Cardiothorac Imaging; 2:e200117. https://doi.org/10.1148/ryct.2020200117

7. Liu H, Liu F, Li J, Zhang T, Wang D, Lan W (2020) Clinical and CT imaging features of the COVID-19 pneumonia: Focus on pregnant women and children. J Infect; 80:e7-e13. https://doi.org/10.1016/j.jinf.2020.03.007

8. Xia W, Shao J, Guo Y, Peng X, Li Z, Hu D (2020) Clinical and CT features in pediatric patients with COVID-19 infection: Different points from adults. Pediatr Pulmonol; 55:1169-1174. https://doi.org/10.1002/ppul.24718

9. Caro-Dominguez P, Shelmerdine SC, Toso S, et al (2020) Thoracic imaging of coronavirus disease 2019 (COVID-19) in children: a series of 91 cases. Pediatr Radiol; 50: 1354-1368. https://doi.org/10.1007/s00247-020-04747-5 
10. Hansell DM, Bankier AA, MacMahon H, McLoud TC, Müller NL, Remy J (2008) Fleischner Society: Glossary of Terms for Thoracic Imaging. Radiology; 246: 697-722. https://doi.org/10.1148/radiol.2462070712

11. Feinstein AR, Cicchetti DV. High agreement but low kappa: I. The problems of two paradoxes. J Clin Epidemiol. 1990;43(6):543-9. doi: 10.1016/0895-4356(90)90158-l. PMID: 2348207.

12. Brennan RL, Prediger DJ. Coefficient Kappa: Some Uses, Misuses, and Alternatives. Educational and Psychological Measurement. 1981;41(3):687-699. doi:10.1177/001316448104100307

13. Qiu, H., Wu, J., Hong, L., Luo, Y., Song, Q., \& Chen, D (2020) Clinical and epidemiological features of 36 children with coronavirus disease 2019 (COVID-19) in Zhejiang, China: an observational cohort study. The Lancet Infectious Diseases, 20(6), 689-696. https://doi.org/10.1016/s1473-3099(20)30198-5.

14. Biko DM, Ramirez-Suarez KI, Barrera CA, et al. Imaging of children with COVID-19: experience from a tertiary children's hospital in the United States [published online ahead of print, 2020 Sep 18]. Pediatr Radiol. 2020;1-9. doi:10.1007/s00247-020-04830-x.

15. Neuman MI, Lee EY, Bixby S, Diperna S, Hellinger J, Markowitz R, Servaes S, Monuteaux MC, Shah S (2012) Variability in the interpretation of chest radiographs for the diagnosis of pneumonia in children. Journal of Hospital Medicine; 7(4): 294-298. DOI:10.1002/jhm.955

16. Deng Q, Ou C, Chen J, Xiang Y (2018) Particle deposition in tracheobronchial airways of an infant, child and adult. Sci Total Environ; 612:339-346. DOI: 10.1016/j.scitotenv.2017.08.240

17. Varga Z, Flammer AJ, Steiger P, et al (2020) Endothelial cell infection and endotheliitis in Covid-19. Lancet; 395:1417-1418. https://doi.org/10.1016/S0140-6736(20)30937-5 
18. Lai W, Xie C, Pan H, Fan M, Liu J (2020) Computed tomography of the lungs in novel coronavirus (COVID-19) infection. Pediatr Radiol; 50:1016-1017. https://doi.org/10.1007/s00247-020-04664-7

19. Steinberger S, Lin B, Bernheim A, Chung M, Gao Y, Xie Z (2020) CT Features of Coronavirus Disease (COVID-19) in 30 Pediatric Patients. AJR; 215:1-9. DOI.org/10.2214/AJR.20.23145

20. Wang Y, Dong C, Hu Y, et al (2020) Temporal changes of CT findings in 90 patients with COVID-19 pneumonia: a longitudinal study. Radiology; 296:E55-E64.18. https://doi.org/10.1148/radiol.2020200843

21. Berheim A, Mei X, Huang M, et al (2020) Chest CT findings in coronavirus disease-19 (Covid-19): Relationship to Duration of Infection. Radiology; 295:685-691. https://doi.org/10.1148/radiol.2020200463

22. Kanne JP (2020) Chest CT findings in 2019 novel coronavirus (2019 n-CoV) infection from Wuhan, China: key points for the radiologist. Radiology; 295: 16-17. https://doi.org/10.1148/radiol.2020200241

23. Kim H (2020) Outbreak of novel coronavirus (Covid-19): What is the role of radiologist?. Eur Radiol; 30:3266-3267. https://doi.org/10.1007/s00330-020-06748-2

24. Duan Y, Zhu Y, Tang L, Qin J (2020) CT features of novel coronavirus pneumonia (COVID19) in children. Eur Radiol; 30:4427-4433. https://doi.org/10.1007/s00330-020-068603

25. Salehi S, Abedi A, Balakrishnan S, Gholamrezanezhad A (2020) Coronavirus disease 2019 (COVID-19): A systematic review of imaging findings in 919 patients. AJR; 215:87-93. DOI: 10.2214/AJR.20.23034

26. Pan F, Ye T, Sun P, et al (2020) Time course of lung changes at chest CT during recovery from coronavirus disease 2019 (COVID-19). Radiology; 295:715-721. https://doi.org/10.1148/radiol.2020200370 
27. Kong W, Agarwal PP (2020) Chest imaging appearance of COVID-19 infection. Radiol Cardiothorac Imaging; 2:e200028. https://doi.org/10.1148/ryct.2020200028

28. Yin Z, Kang Z, Yang D, Ding S, Luo H, Xiao E (2020) A Comparison of Clinical and Chest CT Findings in Patients With Influenza A (H1N1) Virus Infection and Coronavirus Disease (COVID-19). AJR; 215:1-7. DOI: 10.2214/AJR.20.23214

29. Lang M, Som A, Carey D, et al (2020) Pulmonary vascular manifestation of Covid-19 $\begin{array}{llll}\text { pneumonia. } & \text { Radiol } & \text { Cardiothorac }\end{array}$ https://doi.org/10.1148/ryct.2020200277

30. Parry AH, Wani AH (2020) Segmental Pulmonary Vascular Changes in COVID-19 Pneumonia. AJR; 215:W33.28. DOI: 10.2214/AJR.20.23443

31. Ackerman M, Verleden SE, Kuehnel M, et al (2020) Pulmonary vascular endothelialitis, thrombosis and angiogenesis in Covid-19. N Eng J Med; 383:120-128. DOI: 10.1056/NEJMoa2015432

32. Cavagna E, Muratore F, Ferrari F (2020) Pulmonary thromboembolism in Covid-19: Venous thromboembolism or arterial thrombosis?. Radiol Cardiothorac Imaging; 2:4. https://doi.org/10.1148/ryct.2020200289

33. Meyers MA, McGuire PV (1995) Spiral CT demonstration of hypervascularity in Crohn's disease: "vascular jejunization of the ileum" or the "comb sign". Abdom Imaging;20:327332. https://doi.org/10.1007/BF00203365

34. Brito Panizza P. Cavalcante Viana P, Horvat N, Ribeiro dos Santos Júnior V, Pucci de Araújo D (2017) Inflammatory Bowel Disease: Current Role of Imaging in Diagnosis and Detection of Complications: Gastrointestinal Imaging. RadioGraphics; 37:701-702. https://doi.org/10.1148/rg.2017160050

35. Lu X, Zhang L, Du H et al (2020) SARS Cov-2 infection in children. N Engl J Med; 382: 16631665. DOI: $10.1056 /$ NEJMc2005073 
36. Li W, Cui H, Li K, Fang Y, Li S (2020) Chest computed tomography in children with COVID19 respiratory infection. Pediatr Radiol; 50:796-799. https://doi.org/10.1007/s00247020-04656-7 
Table 1. Clinical and pulmonary findings of 140 Latin American children with COVID-19

\begin{tabular}{c}
\multicolumn{2}{c}{ Total } \\
\hline $\mathrm{n}$
\end{tabular}

\section{Clinical features}

Age (years)

Median IQR

$0-6$ years

$6.2 \quad 1.6-12.1$

$6-13$ years

$66 \quad 47.1$

$>13$ years

$42 \quad 30.0$

$32 \quad 22.9$

Female

$\begin{array}{ll}71 & 50.7\end{array}$

Patients with symptom data

137

Symptomatic

$117 \quad 85.4$

Fever

$83 \quad 60.6$

Dyspnea

$39 \quad 28.5$

Cough

$27 \quad 19.7$

Tachypnea

$22 \quad 16$

Tachycardia

$9 \quad 6.5$

Rhinorrhea

$6 \quad 4.3$

Productive cough

$5 \quad 3.6$

Odynophagia

$5 \quad 3.6$

Comorbidities

$\begin{array}{ll}92 & 65.7\end{array}$

Patients with Clinical outcome data

Favorable

$85 \quad 62.5$

ICU admission

$32 \quad 23.5$

Mechanical ventilation

$7 \quad 5.1$

Death

$12 \quad 8.8$

Days from symptom onset to exam date

X Ray (mean, SD)

$2.3 \quad 2.3$

Median, IQR

$1 \quad 1-3$

CT (mean, SD)

$8.8 \quad 10.1$

Median IQR

$6.59 .5-11.5$

Imaging findings

Chest X Ray

Peribronchial Thickening

122

93.1

Ground glass opacity

$103 \quad 78.6$

Vascular Engorgement

$82 \quad 62.6$

Consolidation

$43 \quad 32.8$


Predominant vascular engorgement *

$25 \quad 21.9$

Pleural effusion

$8 \quad 6.1$

Atelectasis

$3 \quad 2.3$

Computed Tomography

32

Ground glass

$29 \quad 90.6$

Vascular Engorgement

$27 \quad 84.4$

Peribronchial thickening

$23 \quad 71.9$

Consolidation

$22 \quad 68.8$

Halo

$12 \quad 37.5$

Reverse halo

$11 \quad 34.4$

Crazy Paving

$10 \quad 31.3$

Linear Opacity

$5 \quad 15.6$

Pleural effusion

$4 \quad 12.9$

Nodule

* Total excluding cardiovascular underlying conditions IQR interquartile range.

Relative frequencies were calculated on valid results 
Table 2. Chest radiographic findings in 131 Latin American children with COVID-19

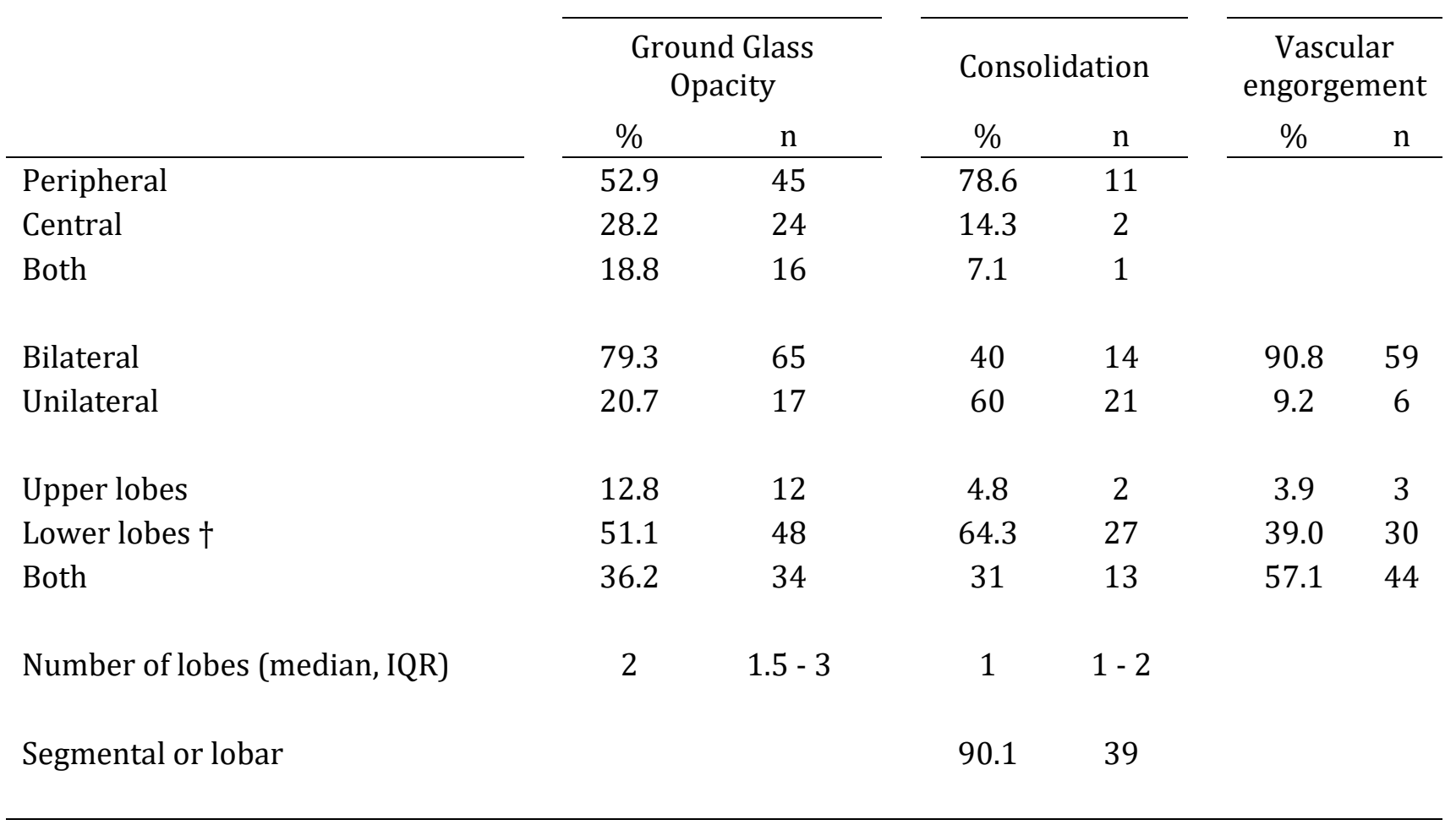

† Middle lobe was considered as lower lobe.

Relative frequencies were calculated on valid results 
Table 3. Chest radiographic and tomographic findings frequencies (\%) by clinical characteristics

\begin{tabular}{|c|c|c|c|c|c|c|c|c|c|c|c|c|}
\hline & \multicolumn{4}{|c|}{ Age (years) } & \multicolumn{3}{|c|}{ Symptomatic } & \multicolumn{3}{|c|}{$\begin{array}{c}\text { ICU admission or } \\
\text { death }\end{array}$} & \multicolumn{2}{|c|}{$\begin{array}{r}\text { Days from } \\
\text { symptoms on: }\end{array}$} \\
\hline & 0 to $<6$ & $\begin{array}{l}6 \text { to } \\
<13 \\
\end{array}$ & $>=13$ & & Yes & No & & Yes & No & & $<7$ days & $>=$ \\
\hline $\begin{array}{l}\text { Radiological } \\
\text { features }\end{array}$ & $(n=63)$ & $(n=38)$ & $(n=30)$ & & $(n=109)$ & $(n=19)$ & & $(n=46)$ & $(n=81)$ & & $(n=109)$ & $(n=$ \\
\hline $\begin{array}{l}\text { Vascular } \\
\text { Engorgement }\end{array}$ & 54.0 & 79.0 & 60.0 & $*$ & 59.6 & 73.7 & & 47.8 & 69.1 & $*$ & 62.4 & \\
\hline $\begin{array}{l}\text { Peribronchial } \\
\text { Thickening }\end{array}$ & 92.1 & 97.4 & 90.0 & & 91.7 & 100.0 & & 84.7 & 97.5 & $*$ & 92.7 & \\
\hline Hazy Opacity & 88.9 & 71.1 & 66.7 & $*$ & 76.2 & 89.5 & & 91.3 & 70.4 & $*$ & 79.8 & \\
\hline Consolidation & 23.8 & 31.6 & 53.3 & $*$ & 36.7 & 10.5 & $*$ & 47.8 & 23.5 & $*$ & 29.4 & 61 \\
\hline $\begin{array}{l}\text { Predominant } \\
\text { vascular } \\
\text { engorgement } \\
+\end{array}$ & 17.0 & 29.7 & 16.7 & & 21.3 & 23.5 & & 16.7 & 24.3 & & 23.7 & \\
\hline $\begin{array}{l}\text { Tomographic } \\
\text { features }\end{array}$ & $(n=9)$ & $(n=11)$ & $(n=12)$ & & $(n=30)$ & $(n=2)$ & & $(n=17)$ & $(n=15)$ & & $(n=16)$ & $(n=$ \\
\hline $\begin{array}{l}\text { Vascular } \\
\text { Engorgement }\end{array}$ & 77.8 & 100.0 & 75.0 & & 83.3 & 100.0 & & 82.4 & 86.7 & & 93.8 & \\
\hline Ground Glass & 100.0 & 90.9 & 83.3 & & 90.0 & 100.0 & & 94.1 & 86.7 & & 93.8 & 87 \\
\hline Crazy Paving & 22.2 & 27.3 & 41.7 & & 33.3 & 0.0 & & 35.3 & 26.7 & & 25.0 & 37 \\
\hline Consolidation & 66.7 & 63.6 & 75.0 & & 70.0 & 50.0 & & 70.6 & 66.7 & & 68.8 & 68 \\
\hline Halo & 11.1 & 45.5 & 50.0 & & 40.0 & 0.0 & & 35.3 & 40.0 & & 43.8 & \\
\hline Reverse Halo & 33.3 & 18.2 & 50.0 & & 36.7 & 0.0 & & 47.1 & 20.0 & & 43.8 & \\
\hline
\end{tabular}

$* \mathrm{p}<0.05$ fisher's exact chi2

† Totals excluding cardiovascular underlying conditions $(n=114)$ 
Table 4. Imaging finding frequencies among raters and inter-rater agreement

\begin{tabular}{|c|c|c|c|c|c|c|}
\hline \multicolumn{4}{|c|}{ Frequency, \% } & \multicolumn{3}{|c|}{ Inter-rater Agreement } \\
\hline $\begin{array}{c}\text { Overall } \\
\text { frequency } \\
(95 \% \mathrm{CI}) \geq 2 \\
\text { raters }\end{array}$ & $\begin{array}{c}\text { Rater } \\
1\end{array}$ & $\begin{array}{c}\text { Rater } \\
2\end{array}$ & $\begin{array}{c}\text { Rater } \\
3\end{array}$ & $\begin{array}{c}\text { Agreement } \\
\%\end{array}$ & $\begin{array}{c}\text { Fleiss Kappa } \\
\text { (95\% CI) }\end{array}$ & $\begin{array}{c}p \\
\text { value }\end{array}$ \\
\hline
\end{tabular}

\section{Radiological}

\section{features}

Ground glass

opacity

Vascular

engorgement

Peribronchial

thickening

Consolidation

$\begin{array}{llll}\begin{array}{l}78.6(70.7- \\ \quad 84.9)\end{array} & 80.9 & 64.9 & 67.2 \\ \begin{array}{c}62.6(53.9- \\ \quad 70.5)\end{array} & 29.0 & 84.7 & 62.6 \\ \begin{array}{c}93.1(87.2- \\ \quad 96.4)\end{array} & 95.4 & 87.8 & 90.1 \\ \begin{array}{c}32.8(25.2- \\ \quad 41.4)\end{array} & 30.0 & 32.8 & 38.2 \\ \end{array}$

$\begin{array}{llll}67.9 & 0.22 & (0.09- & 0.001 \\ & & 0.36) & \\ 58.9 & 0.13 & (0.04- & 0.01 \\ & & 0.26) & \\ 88.8 & 0.31 & (0.12- & 0.001 \\ & & 0.49) & \\ 80.2 & 0.56 & (0.44- & <0.001 \\ & & 0.67) & \end{array}$

\section{Tomographic}

\section{features}

Ground glass

opacity

Crazy Paving

Vascular

engorgement

Peribronchial

thickening

Halo

Reverse halo

Consolidation

Linear Opacities

\begin{tabular}{|c|c|c|c|}
\hline $\begin{array}{c}90.6(73.3- \\
97.1)\end{array}$ & 68.8 & 90.6 & 93.8 \\
\hline $\begin{array}{c}31.2(18.0- \\
48.6)\end{array}$ & 29.1 & 18.8 & 59.4 \\
\hline $\begin{array}{c}84.4(66.3- \\
93.7)\end{array}$ & 68.8 & 78.1 & 93.8 \\
\hline $\begin{array}{c}71.9(53.1 \text { - } \\
85.2)\end{array}$ & 65.6 & 90.6 & 56.3 \\
\hline $\begin{array}{c}37.5(22.0- \\
56.1)\end{array}$ & 18.8 & 56.3 & 46.9 \\
\hline $\begin{array}{c}34.4(19.5 \text { - } \\
53.1)\end{array}$ & 31.3 & 18.8 & 59.4 \\
\hline $\begin{array}{c}68.8(50.0 \text { - } \\
82.9)\end{array}$ & 46.9 & 68.8 & 78.1 \\
\hline $\begin{array}{c}15.6(6.3- \\
33.7)\end{array}$ & 25.0 & 18.8 & 18.8 \\
\hline
\end{tabular}

$\begin{array}{lllll}79.2 & 0.58 & \begin{array}{l}(0.36- \\ 0.80)\end{array} & <0.001 & * \\ 66.7 & 0.27 & \begin{array}{l}0.01- \\ 0.53)\end{array} & 0.039 & \\ & & & \\ 64.6 & 0.29 & \begin{array}{l}0.05- \\ 0.53)\end{array} & 0.021 & * \\ 68.9 & 0.38 & \begin{array}{l}0.13- \\ \end{array} & 0.004 & * \\ 68.9 & 0.35 & \begin{array}{l}0.62) \\ (0.10-\end{array} & 0.008 & \\ & & 0.60) & & \\ 70.1 & 0.37 & 0.12- & 0.006 & \\ & & 0.62) & & \\ 75.0 & 0.45 & 0.19- & 0.001 & \\ & & 0.71) & & \\ 85.4 & 0.52 & 0.20- & 0.002 & \\ & & 0.84) & & \end{array}$

Fleiss Kappa coefficient, otherwise

stated. CI: Confidence interval

*Brennan-Prediger's Kappa coefficient 


\section{FIGURES}

Fig. 1- Two-year-old asymptomatic girl with juvenile idiopathic arthritis and immunosuppression. Frontal CXR shows central peribronchial thickening, with peribronchial cuffing (arrowhead).

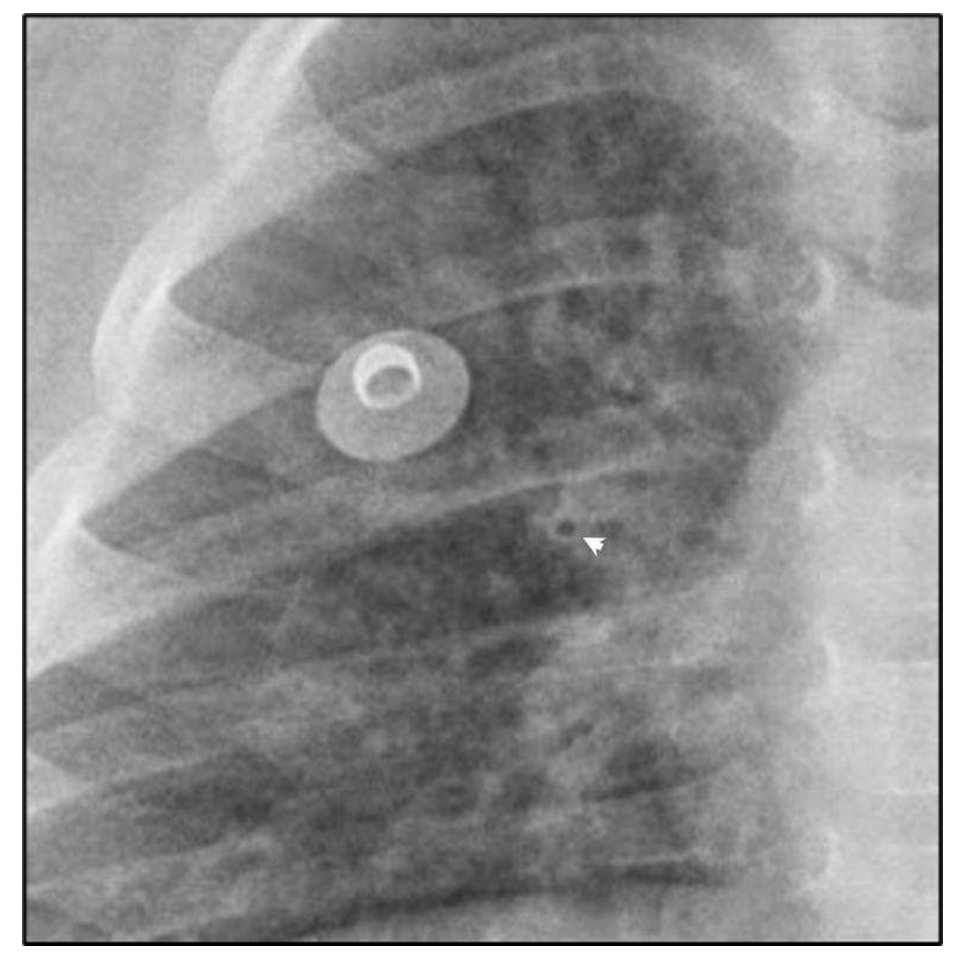

Fig. 2. Eight-day-old asymptomatic female. A portable chest radiograph shows ground-glass opacities, peribronchial thickening and left basal atelectasis (retrocardiac).

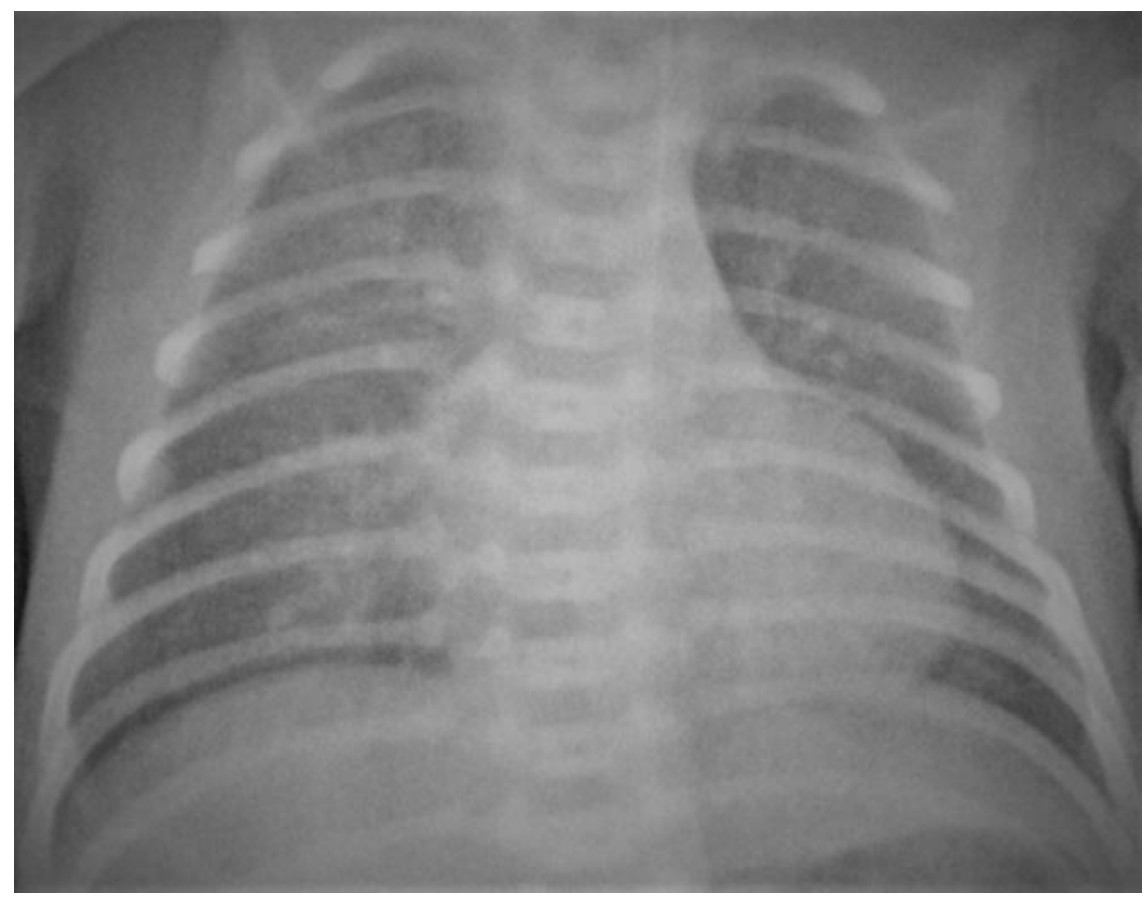


Fig. 3. Six-year-old girl, with leukemia, fever and respiratory distress for two days, hospitalized in the intensive care unit. The portable chest radiograph shows central ill-defined ground-glass opacities, vascular engorgement and consolidation in the right upper lobe.

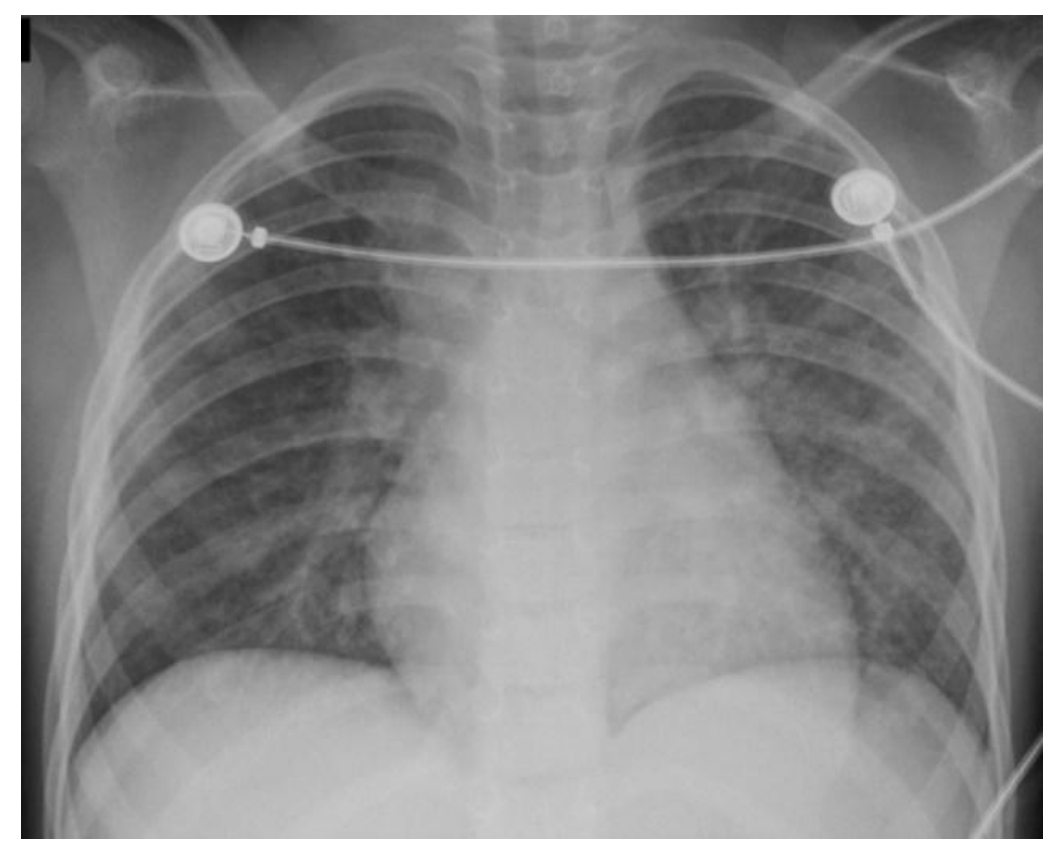

Fig. 4- Five-year-old girl, previously healthy, with fever for three days and clinical suspicion of viral infection of the lower respiratory tract. Frontal chest radiograph shows vascular engorgement more evident on the right side with right perihilar consolidation and ground-glass opacities.

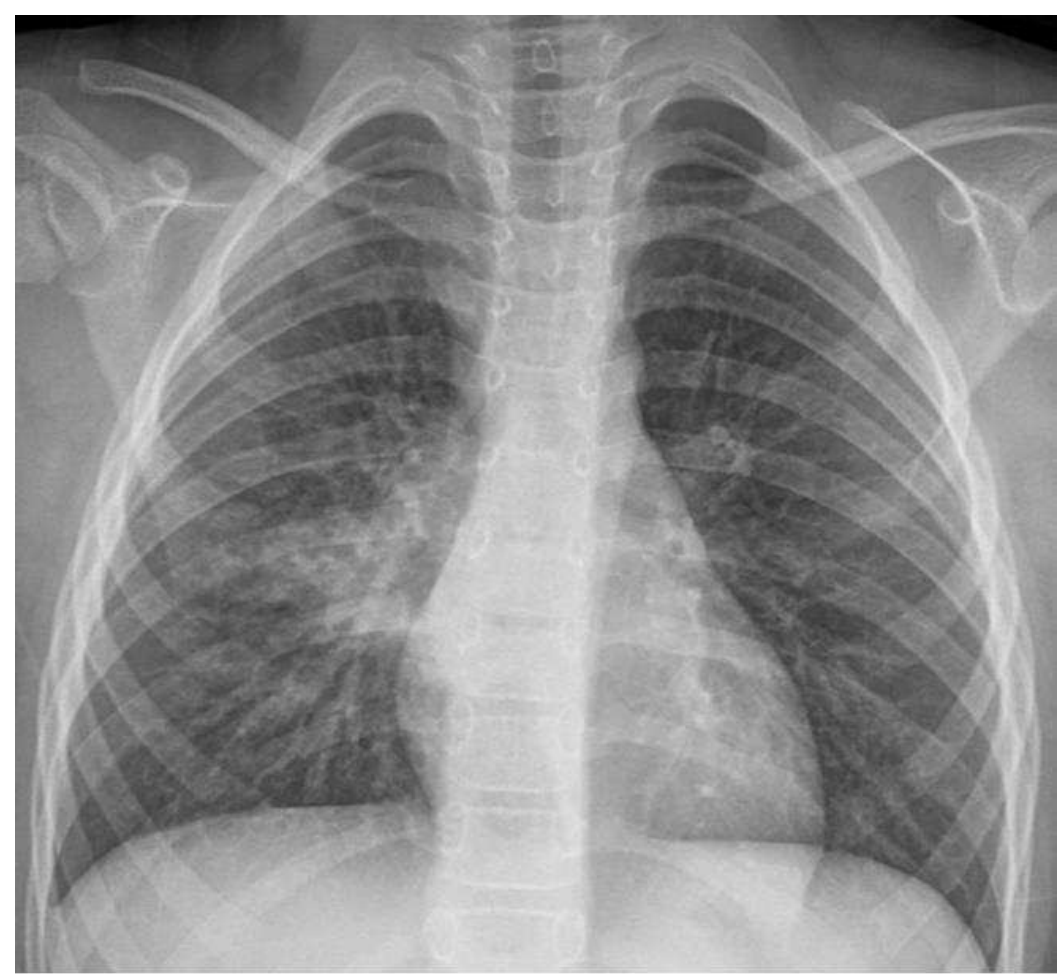


Fig.5- Eleven-year-old boy with fever for 24 h, previously healthy. A. Frontal chest radiograph shows bilateral vascular engorgement B. Left pulmonary base close-up of frontal chest radiograph to show pulmonary vascular engorgement.

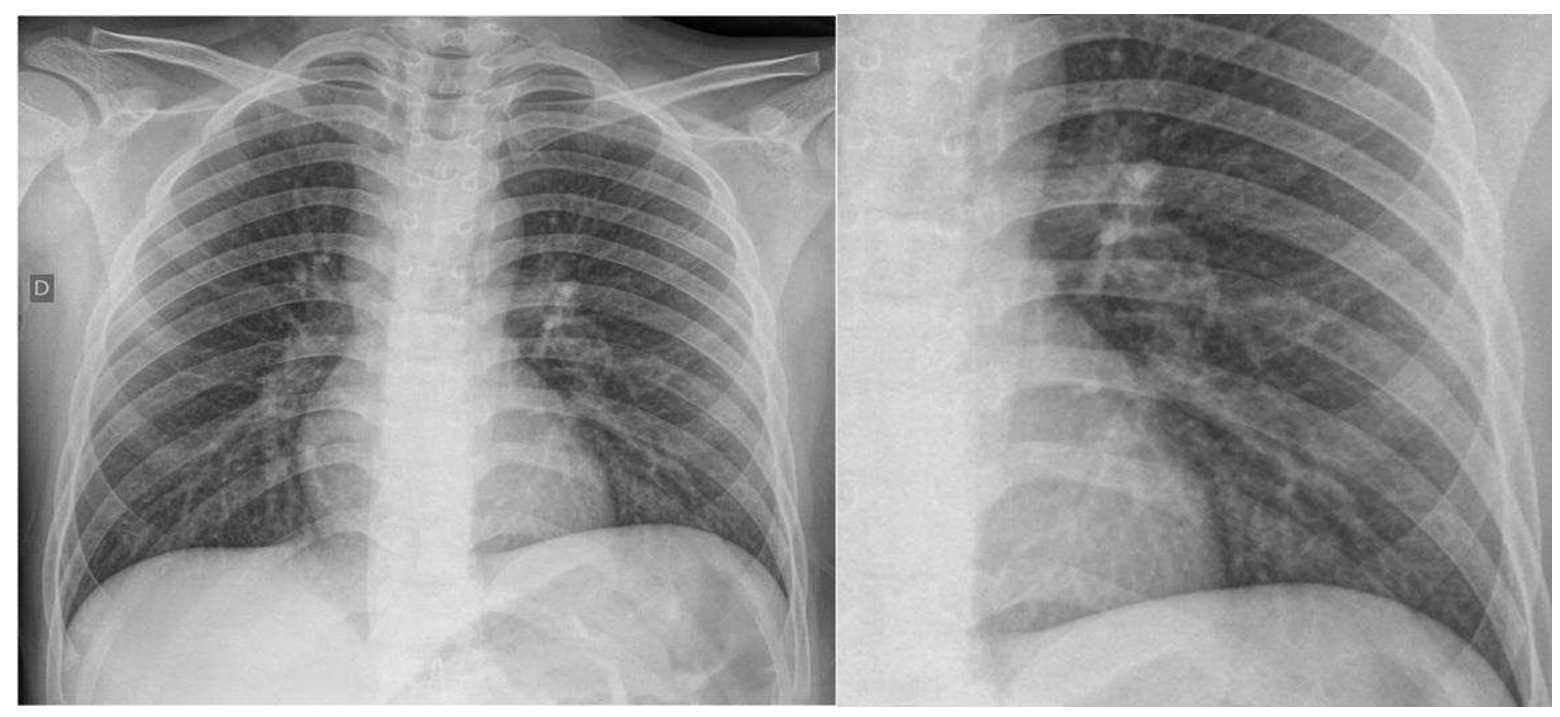

Fig. 6 Twelve-year-old boy, asymptomatic, positive to PCR-RT for SARS-CoV-2. The image was acquired within the first $72 \mathrm{~h}$ of clinical suspicion. A. Frontal chest radiograph shows bilateral vascular engorgement B. Right pulmonary base close-up of frontal chest radiograph shows vascular engorgement to better advantage.

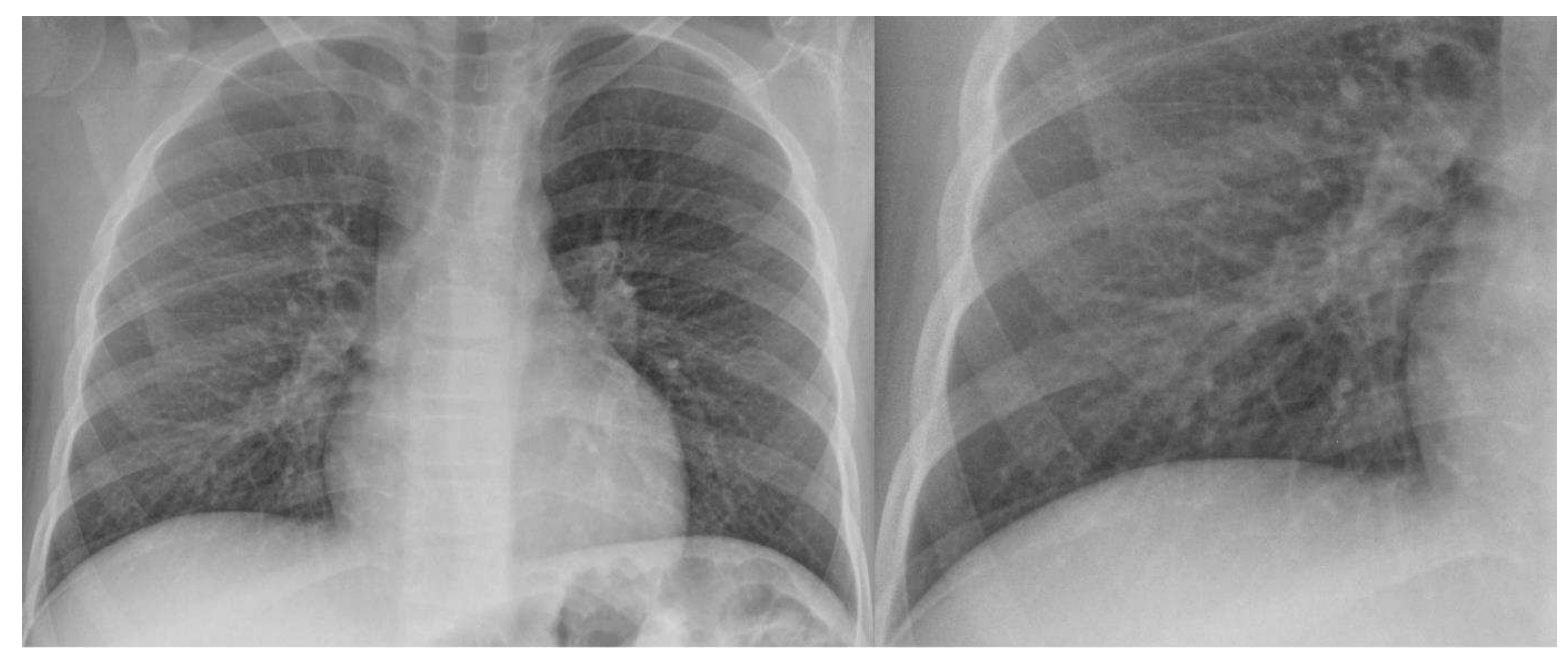


Fig. 7- Thirteen-year-old girl, previously healthy, one day after fever onset and with $\mathrm{O}_{2}$ saturation of $89 \%$, who required intensive care unit admission. (A) At ICU the admission chest radiograph shows subtle right lower lobe vascular engorgement; (B) $24 \mathrm{~h}$ post-admission at ICU, the chest radiograph shows diffuse consolidation in the right lower lobe and right central ground-glass opacity. Her clinical status worsened and chest CT was performed (not shown).

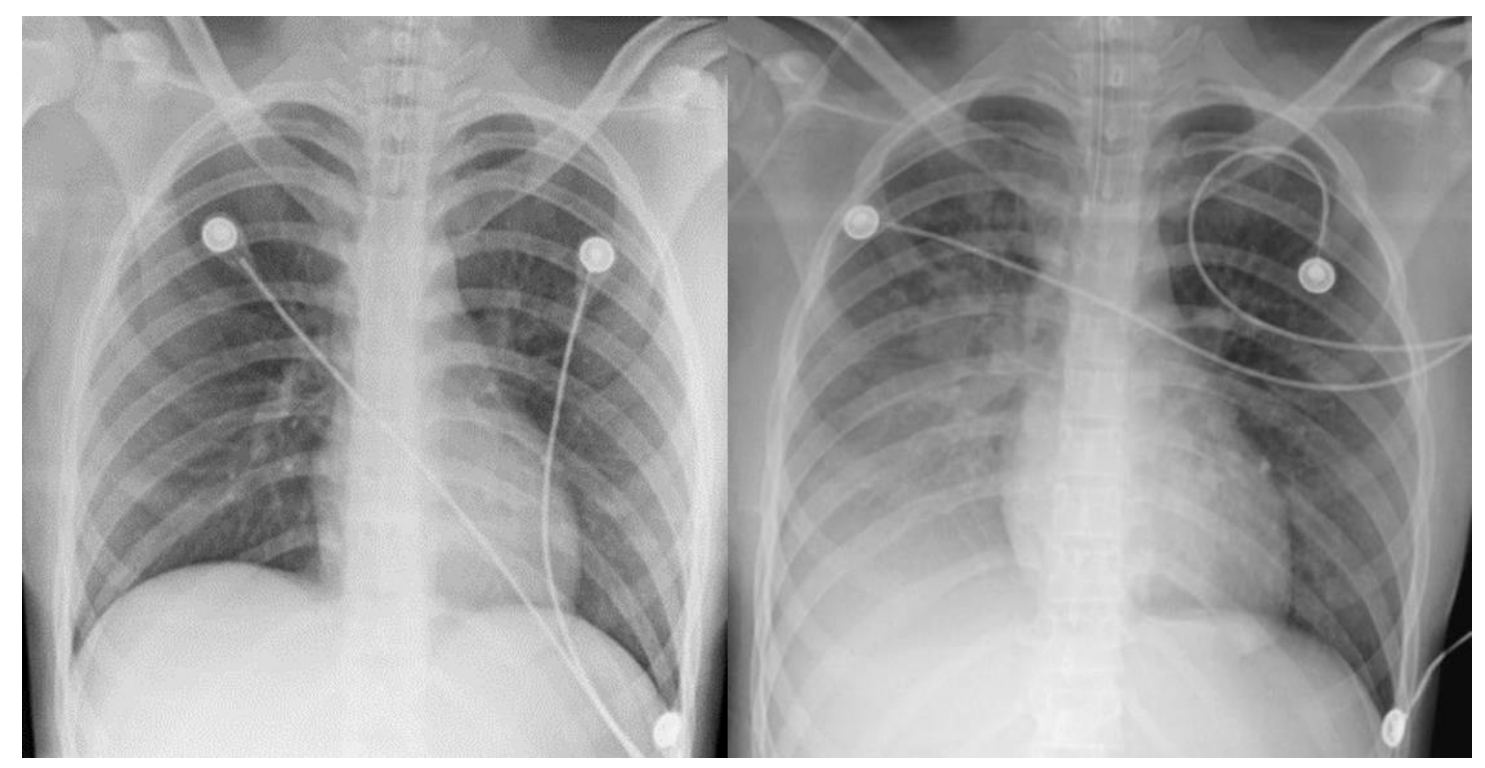

Fig. 8- (A) Fifteen-year-old boy, with leukemia, who presented with diarrhea (suspicion of neutropenic colitis) and clinical deterioration. Axial lung window CT image shows rounded area of ground-glass in the posterior segment of the left upper lobe, with prominent vessels. (B) Same patient with focal peripheral consolidations in the lower lobes, with a "reverse halo" sign (black arrow) containing a dilated vessel.

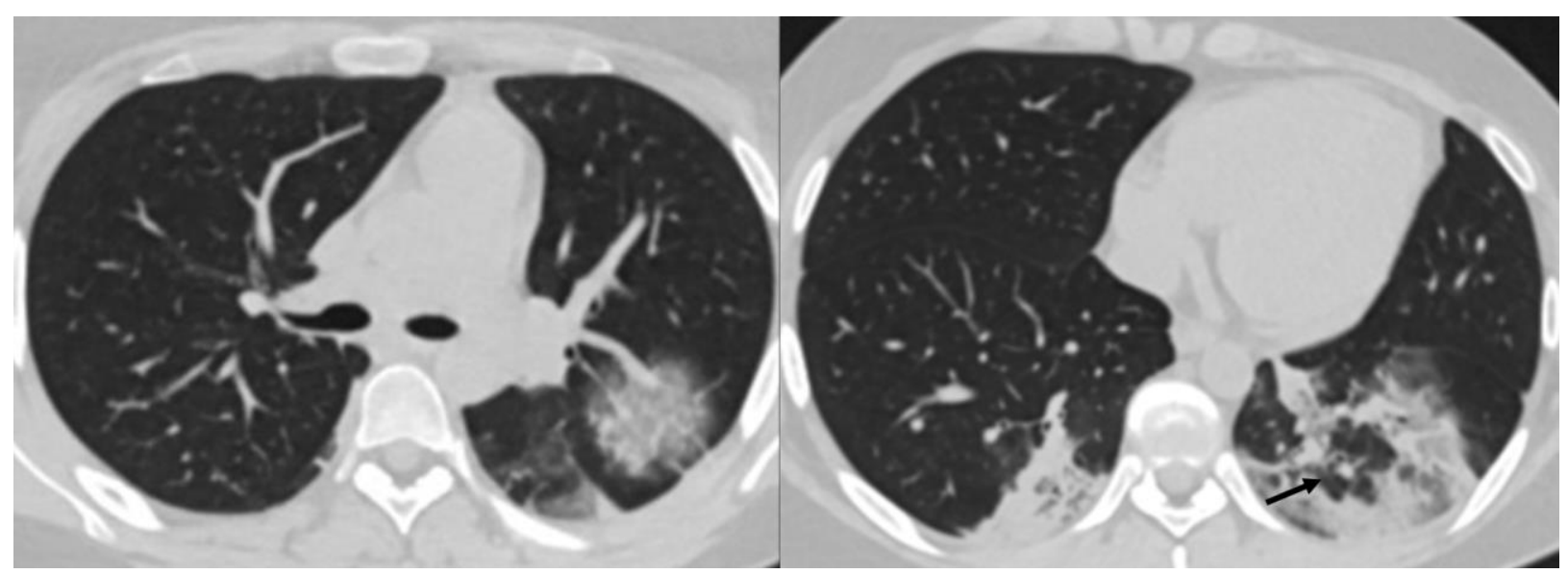


Fig. 9. One-year-old girl with a brain tumor admitted to the intensive care unit for dyspnea and tachypnea. Chest CT was requested on day 14 of hospitalization due to clinical deterioration and no response to treatment. Axial lung window CT image shows peribronchial thickening (arrows)

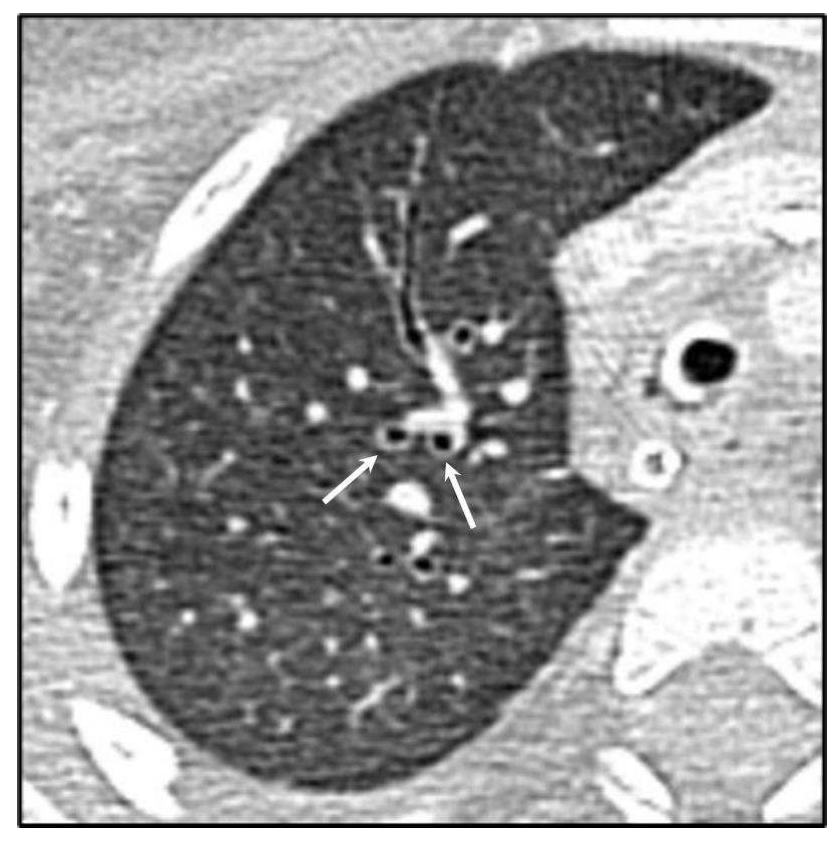

Fig 10. Ten-year-old boy, previously healthy, who presented with fever, dry cough, tachypnea and dyspnea that lasted for three days. Axial lung window CT image shows multifocal pneumonia with multiple ground-glass nodules.

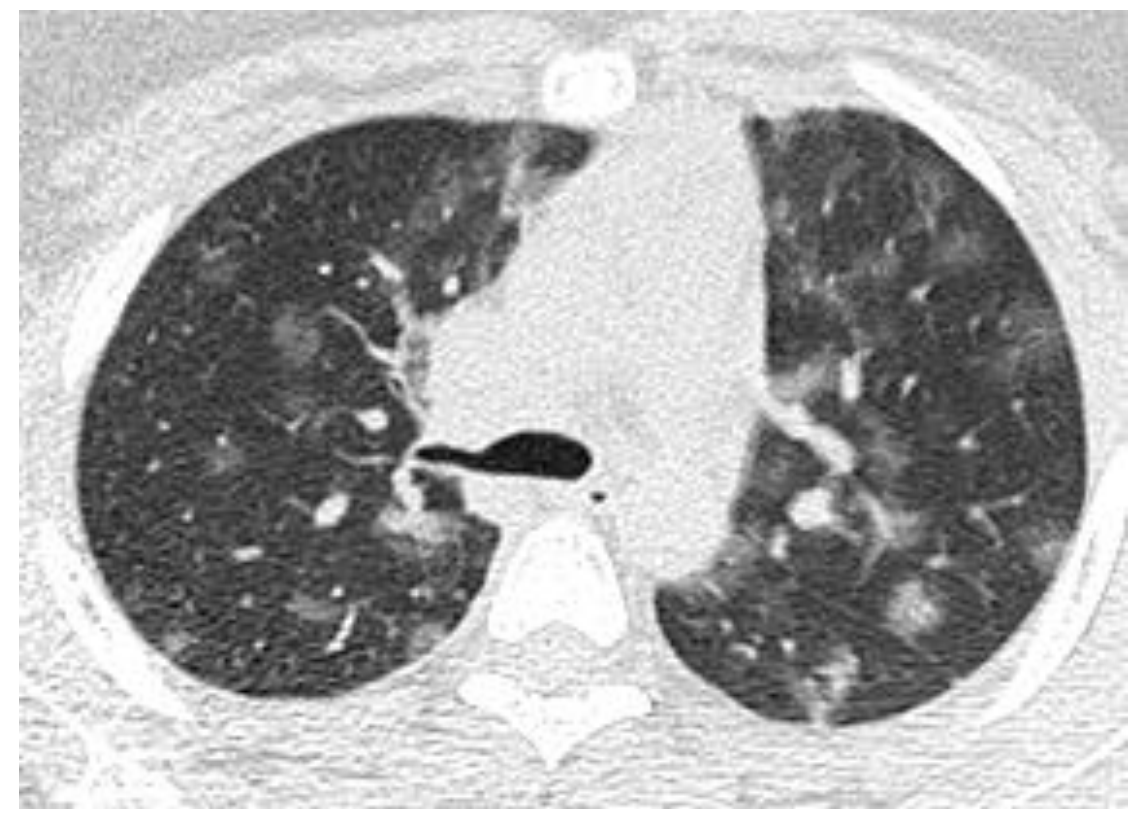


Fig. 11- Ten-year-old girl, with sickle cell anemia presented with cervical pain that lasted one day. A. Frontal chest radiograph shows central peribronchial thickening and bilateral vascular engorgement. B. Axial CT image confirms vascular engorgement and shows parallel vascular tracts that reach the pleural surface (pulmonary comb sign inside the ellipse). C. The presence of peripheral vascular tracts that reach the pleura was corroborated at the sagittal reconstruction lung window CT image (black arrows).
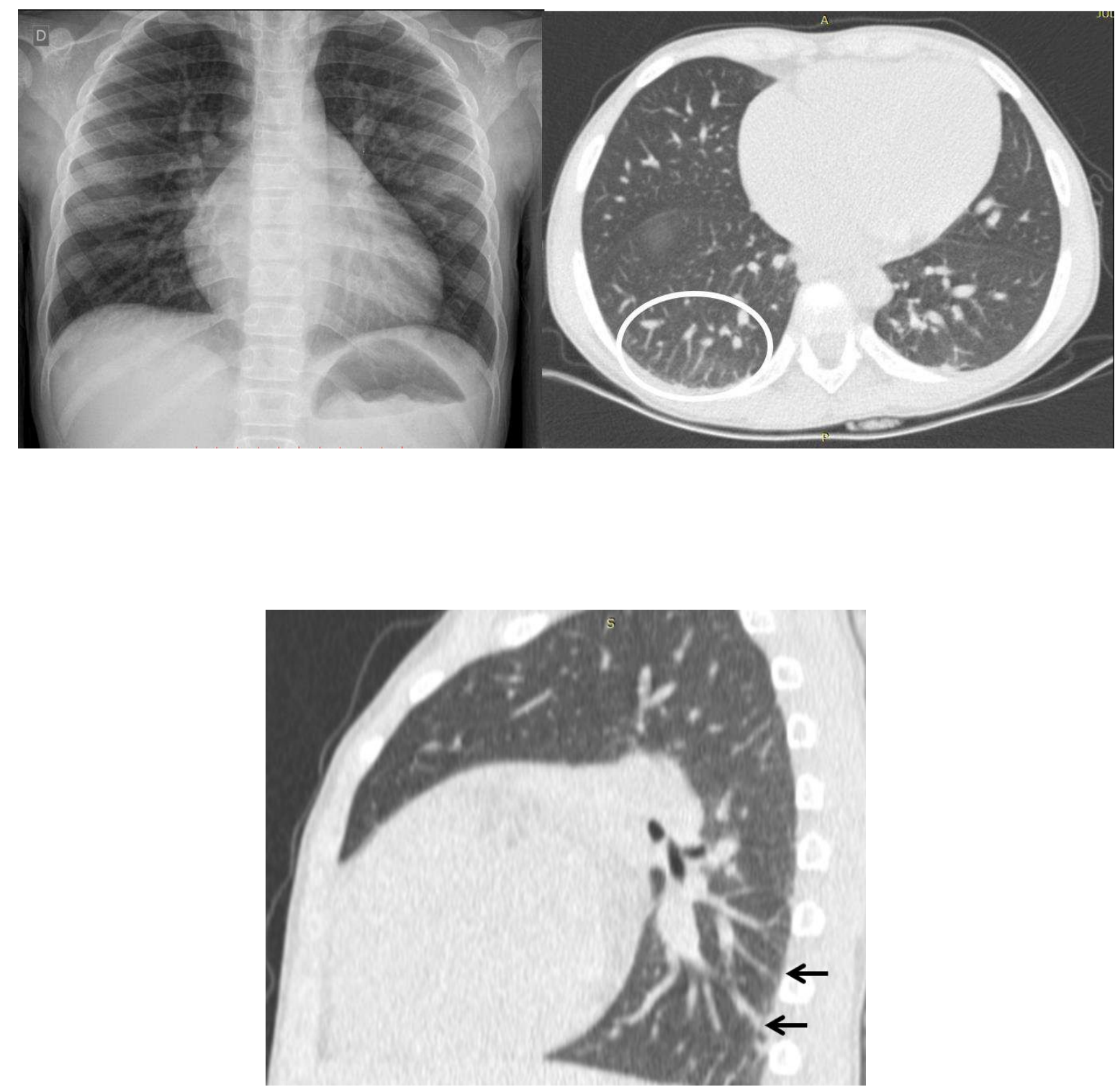


\section{Online Supplementary Material}

Online supplementary material 1, Table 1 shows comorbidities or associated conditions in our cohort.

\begin{tabular}{|l|c|c|}
\hline COMORBIDITIES OR CONDITIONS & n & PERCENTAGE \\
\hline None & 48 & 34.3 \\
Congenital / acquired heart disease & 16 & 11.5 \\
Cancer & 13 & 9.3 \\
Immunodeficiency disorder & 10 & 7.2 \\
Chronic pulmonary disease & 9 & 6.4 \\
Metabolic disorder/obesity & 9 & 6.4 \\
Neurological condition & 8 & 5.7 \\
Burned patient & 6 & 4.3 \\
Orthopedic condition & 6 & 4.3 \\
Gastric/digestive system disease & 6 & 4.3 \\
Other infectious disease & 3 & 2.1 \\
Post-surgical state & 3 & 2.1 \\
Chronic renal disease & 2 & 1.4 \\
Puerperium & 1 & 0.7 \\
\hline
\end{tabular}

Online supplementary material 2, Fig.1: Frequency of chest radiography findings regarding clinical features.

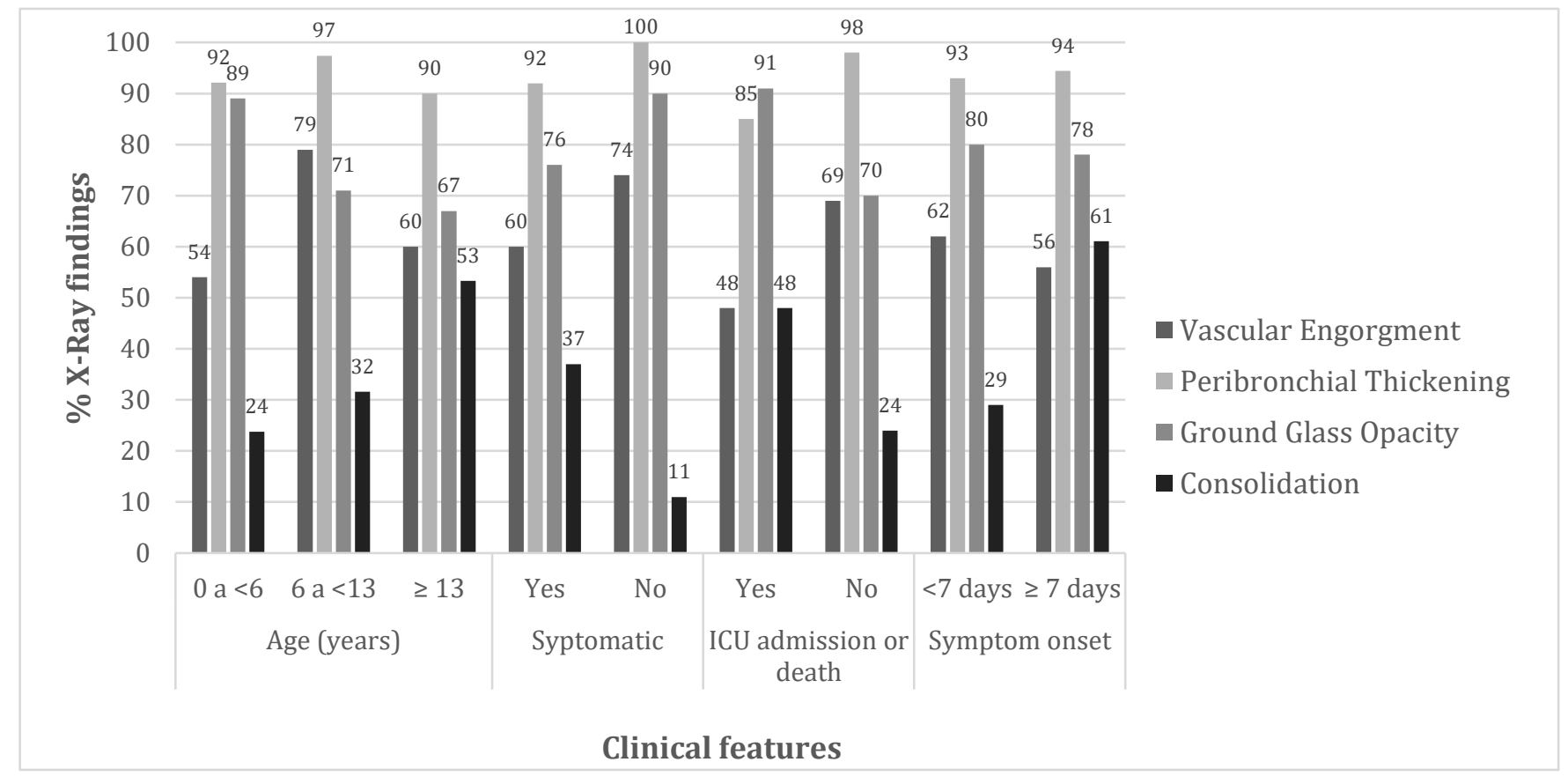


Figures

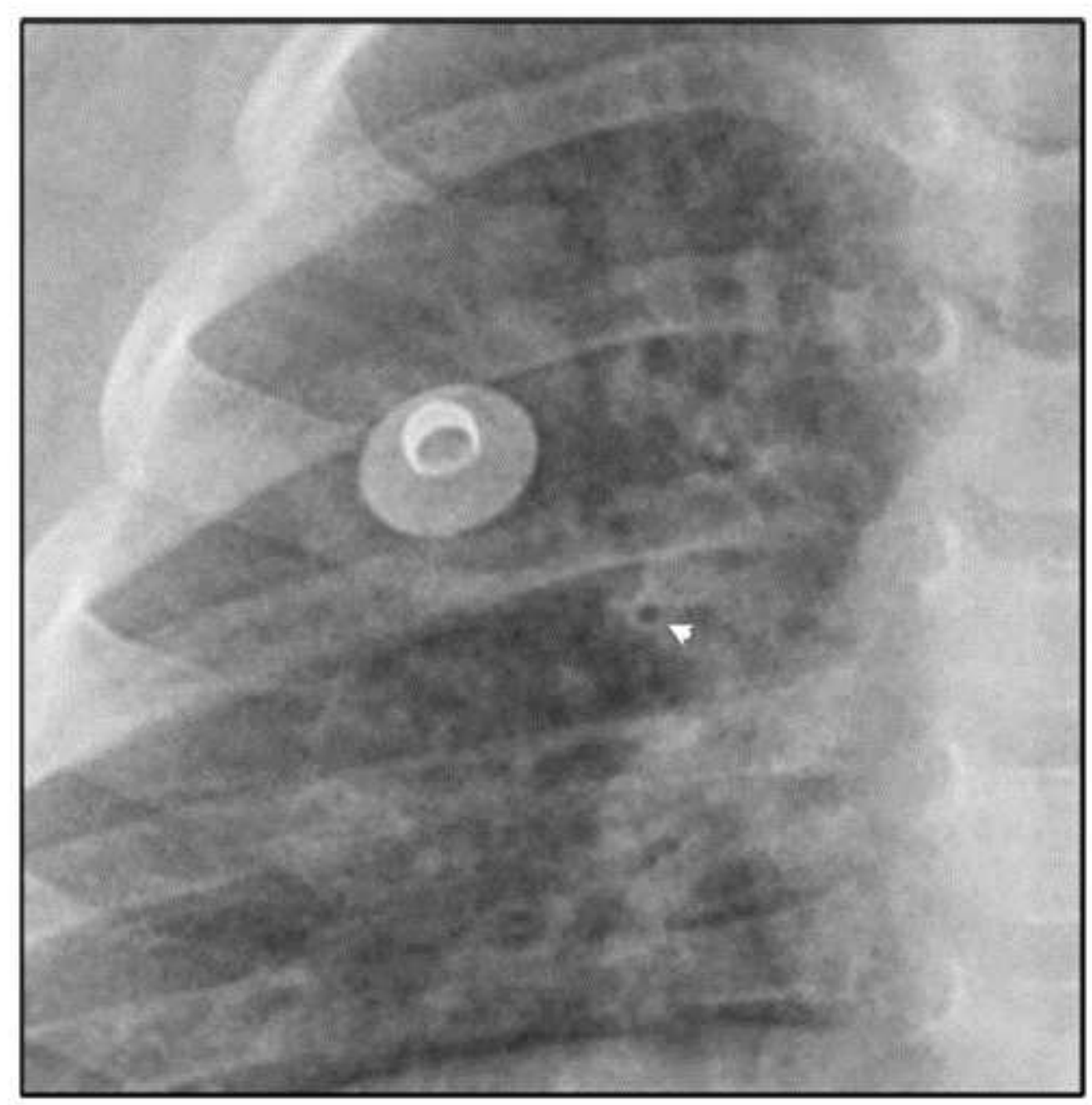

\section{Figure 1}

Two-year-old asymptomatic girl with juvenile idiopathic arthritis and immunosuppression. Frontal CXR shows central peribronchial thickening, with peribronchial cuffing (arrowhead). 


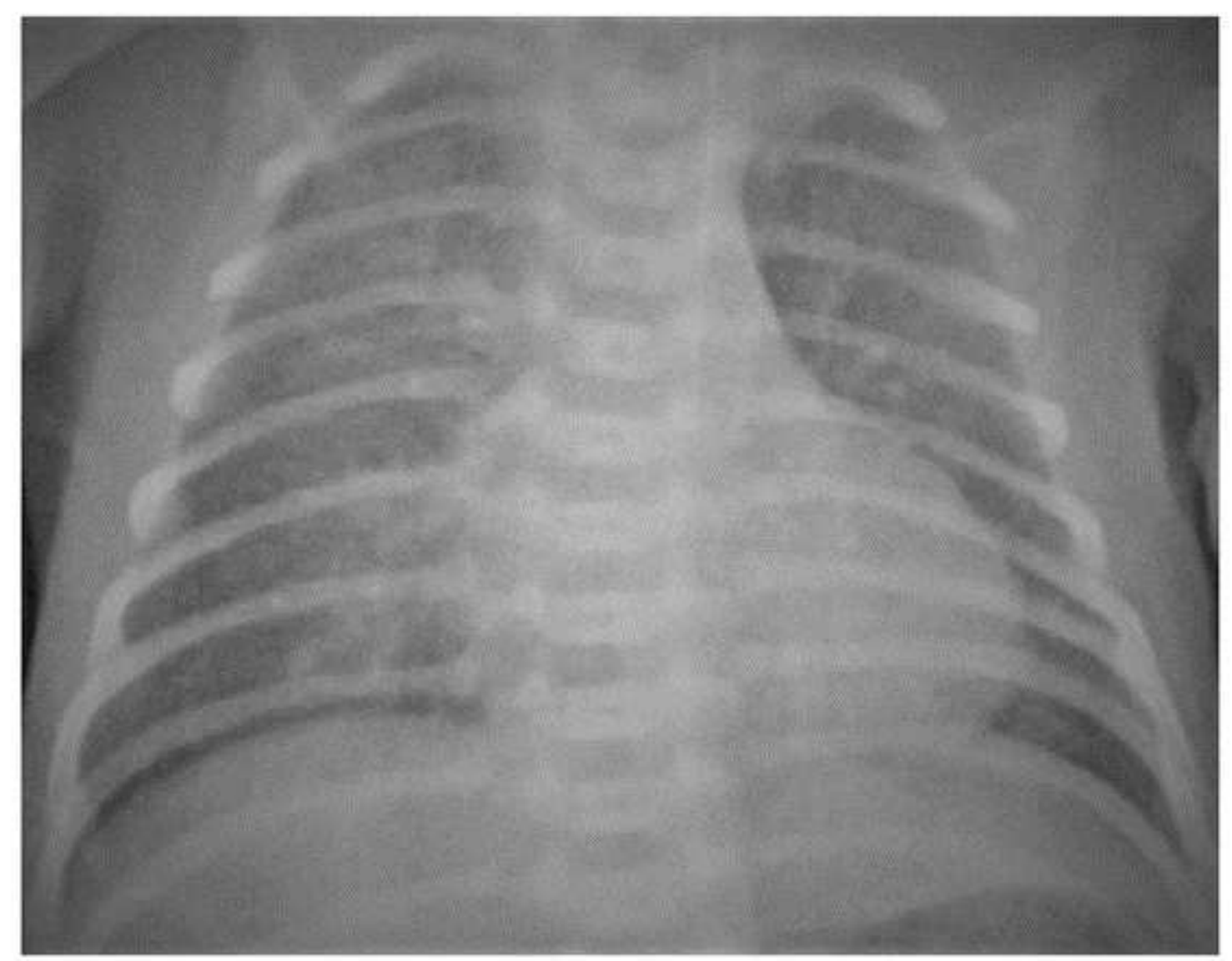

Figure 2

Eight-day-old asymptomatic female. A portable chest radiograph shows ground-glass opacities, peribronchial thickening and left basal atelectasis (retrocardiac). 


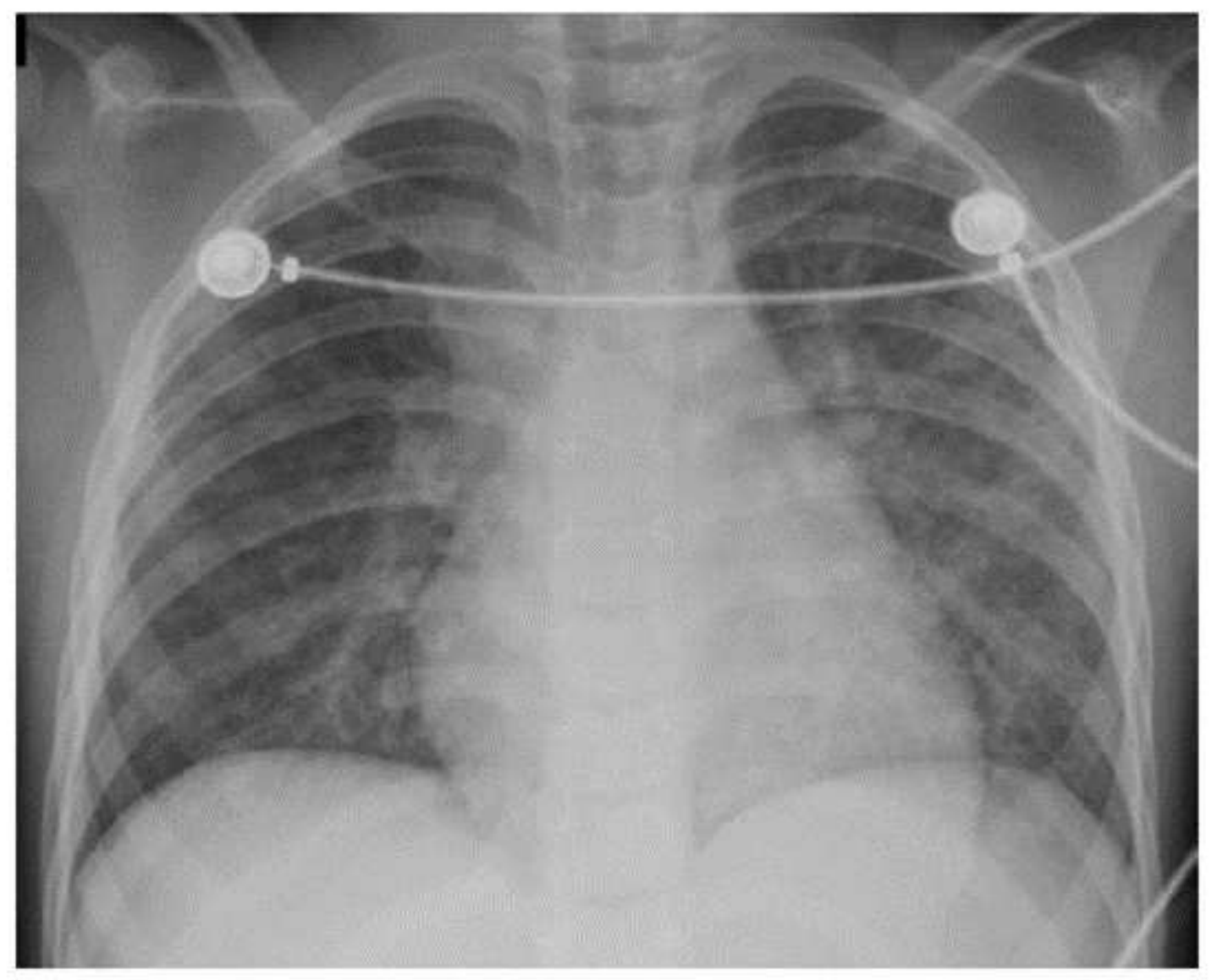

\section{Figure 3}

Six-year-old girl, with leukemia, fever and respiratory distress for two days, hospitalized in the intensive care unit. The portable chest radiograph shows central ill-defined ground-glass opacities, vascular engorgement and consolidation in the right upper lobe. 


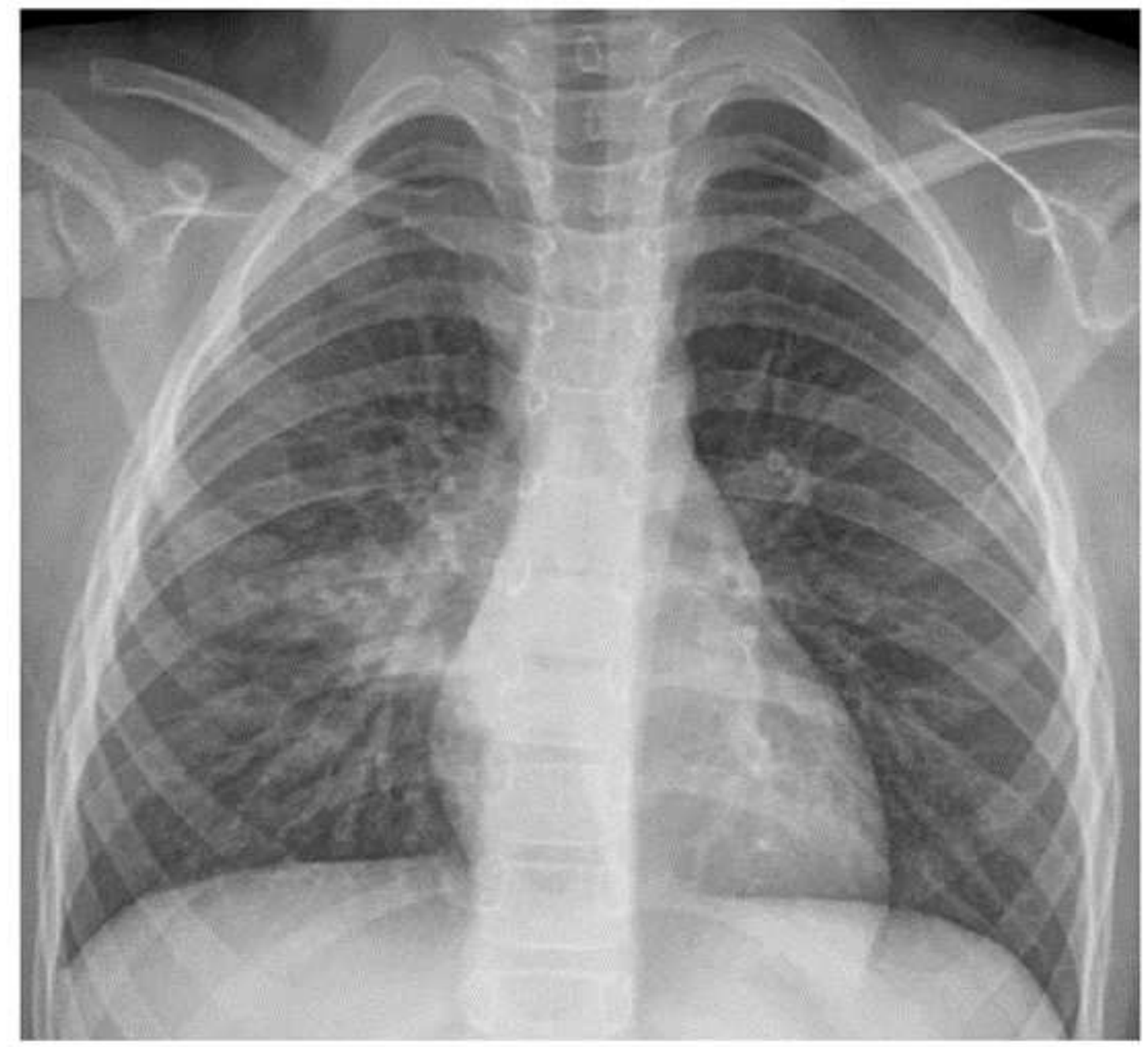

\section{Figure 4}

Five-year-old girl, previously healthy, with fever for three days and clinical suspicion of viral infection of the lower respiratory tract. Frontal chest radiograph shows vascular engorgement more evident on the right side with right perihilar consolidation and ground-glass opacities. 


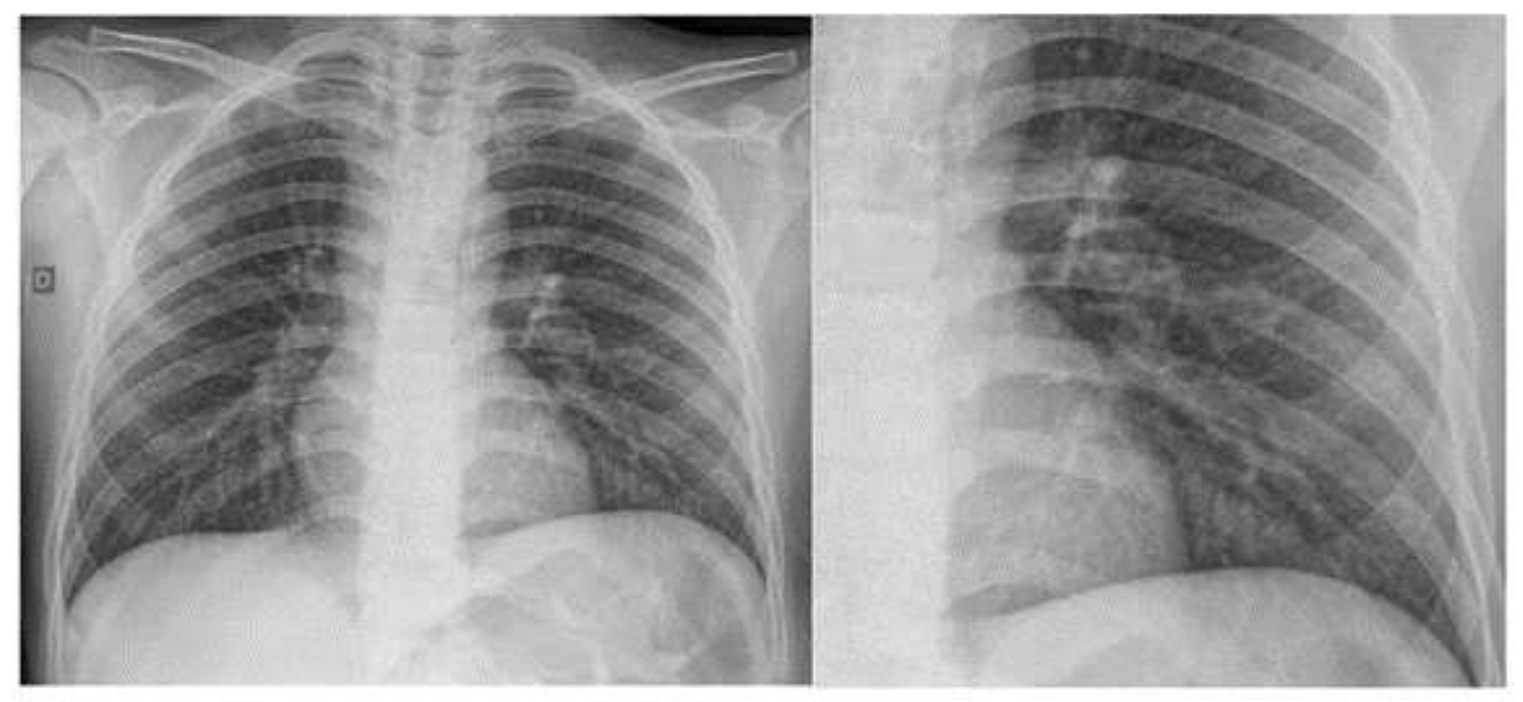

\section{Figure 5}

Eleven-year-old boy with fever for $24 \mathrm{~h}$, previously healthy. A. Frontal chest radiograph shows bilateral vascular engorgement $B$. Left pulmonary base close-up of frontal chest radiograph to show pulmonary vascular engorgement.

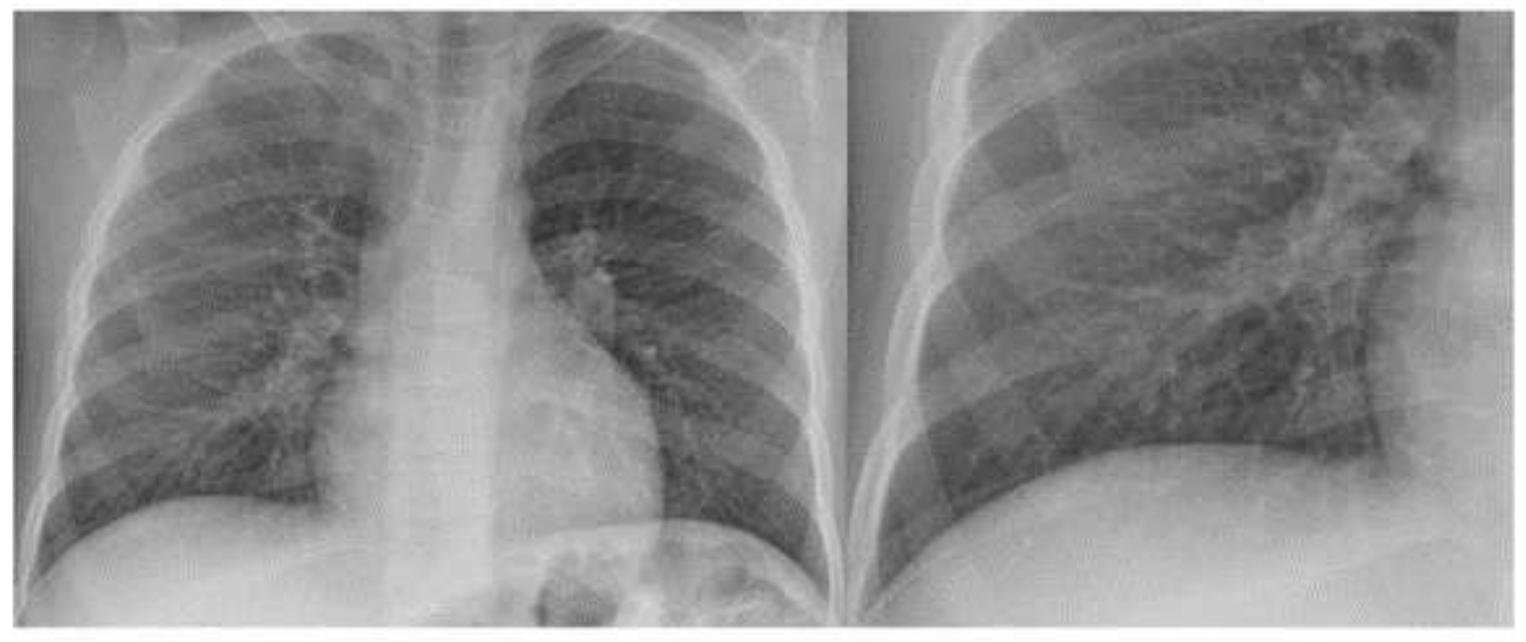

\section{Figure 6}

Twelve-year-old boy, asymptomatic, positive to PCR-RT for SARS-CoV-2. The image was acquired within the first $72 \mathrm{~h}$ of clinical suspicion. A. Frontal chest radiograph shows bilateral vascular engorgement $\mathrm{B}$. Right pulmonary base close-up of frontal chest radiograph shows vascular engorgement to better advantage. 


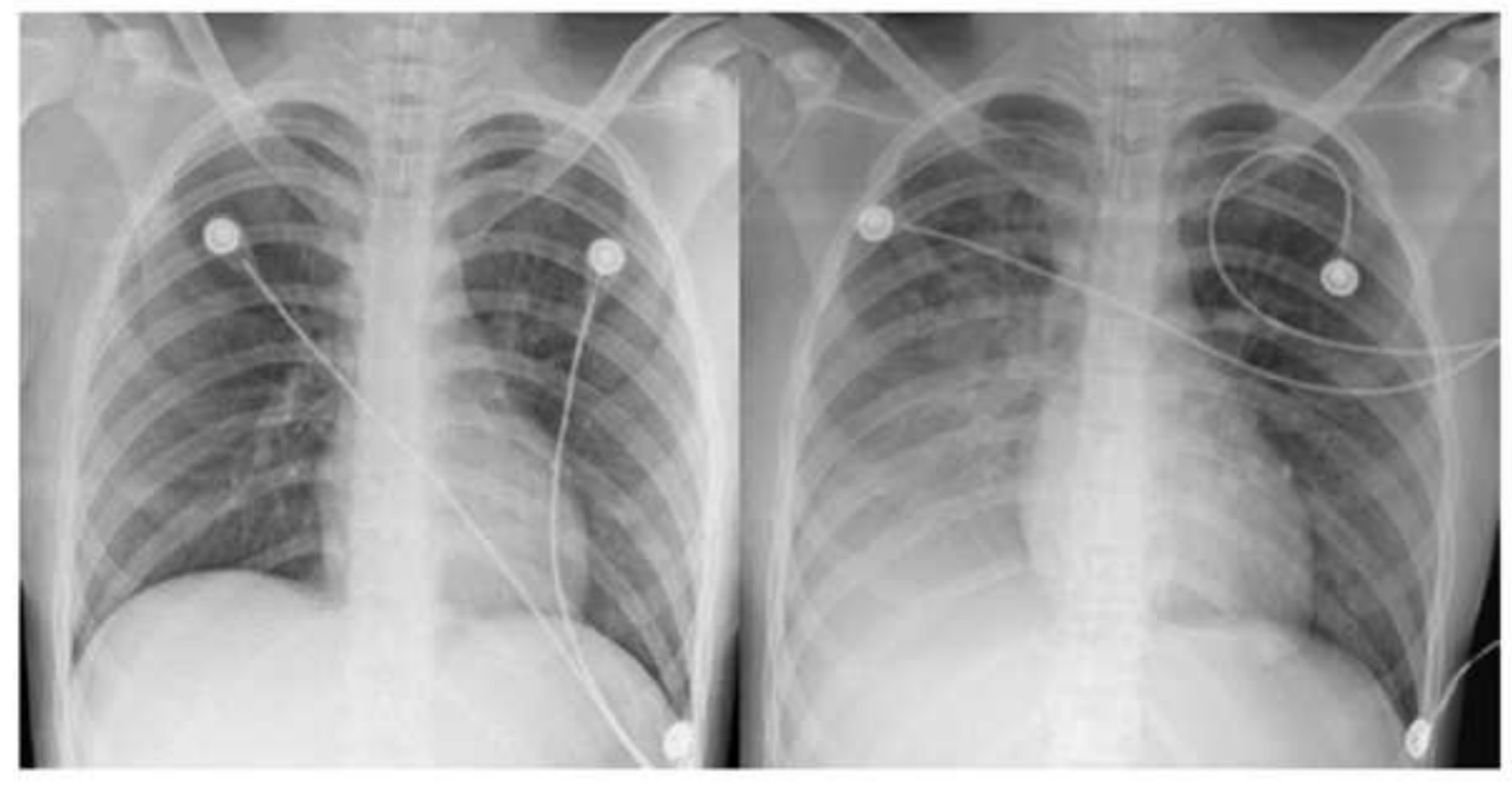

\section{Figure 7}

Thirteen-year-old girl, previously healthy, one day after fever onset and with 02 saturation of $89 \%$, who required intensive care unit admission. (A) At ICU the admission chest radiograph shows subtle right lower lobe vascular engorgement; (B) $24 \mathrm{~h}$ post-admission at ICU, the chest radiograph shows diffuse consolidation in the right lower lobe and right central ground-glass opacity. Her clinical status worsened and chest CT was performed (not shown).

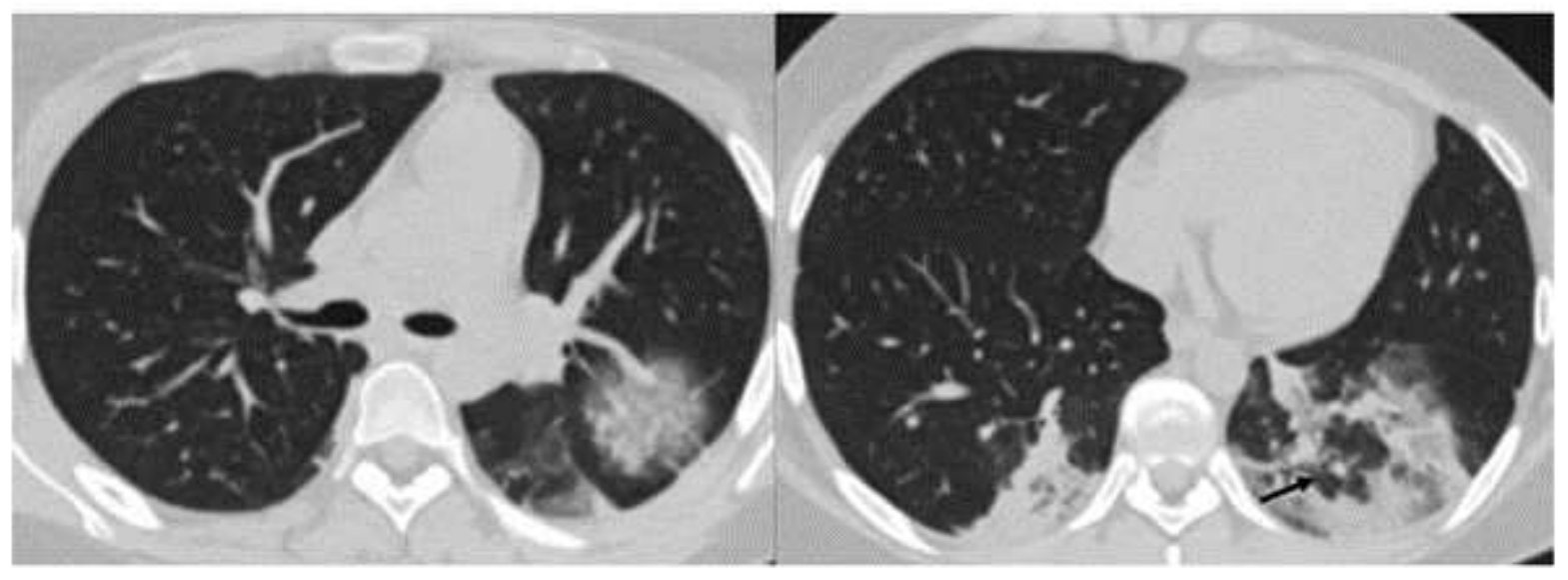

Figure 8

(A) Fifteen-year-old boy, with leukemia, who presented with diarrhea (suspicion of neutropenic colitis) and clinical deterioration. Axial lung window CT image shows rounded area of ground-glass in the posterior 
segment of the left upper lobe, with prominent vessels. (B) Same patient with focal peripheral consolidations in the lower lobes, with a "reverse halo" sign (black arrow) containing a dilated vessel.

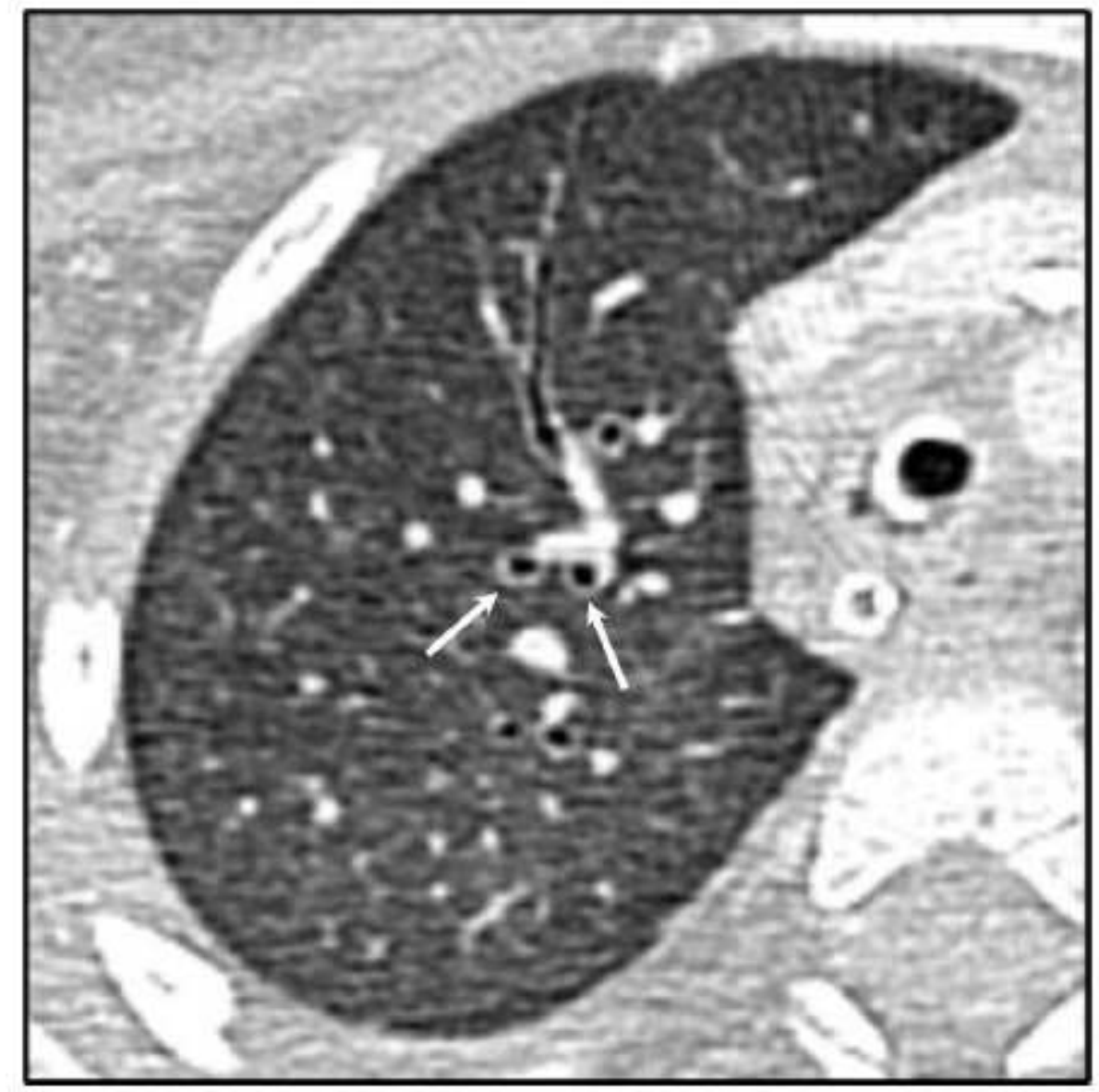

\section{Figure 9}

One-year-old girl with a brain tumor admitted to the intensive care unit for dyspnea and tachypnea. Chest CT was requested on day 14 of hospitalization due to clinical deterioration and no response to treatment. Axial lung window CT image shows peribronchial thickening (arrows) 


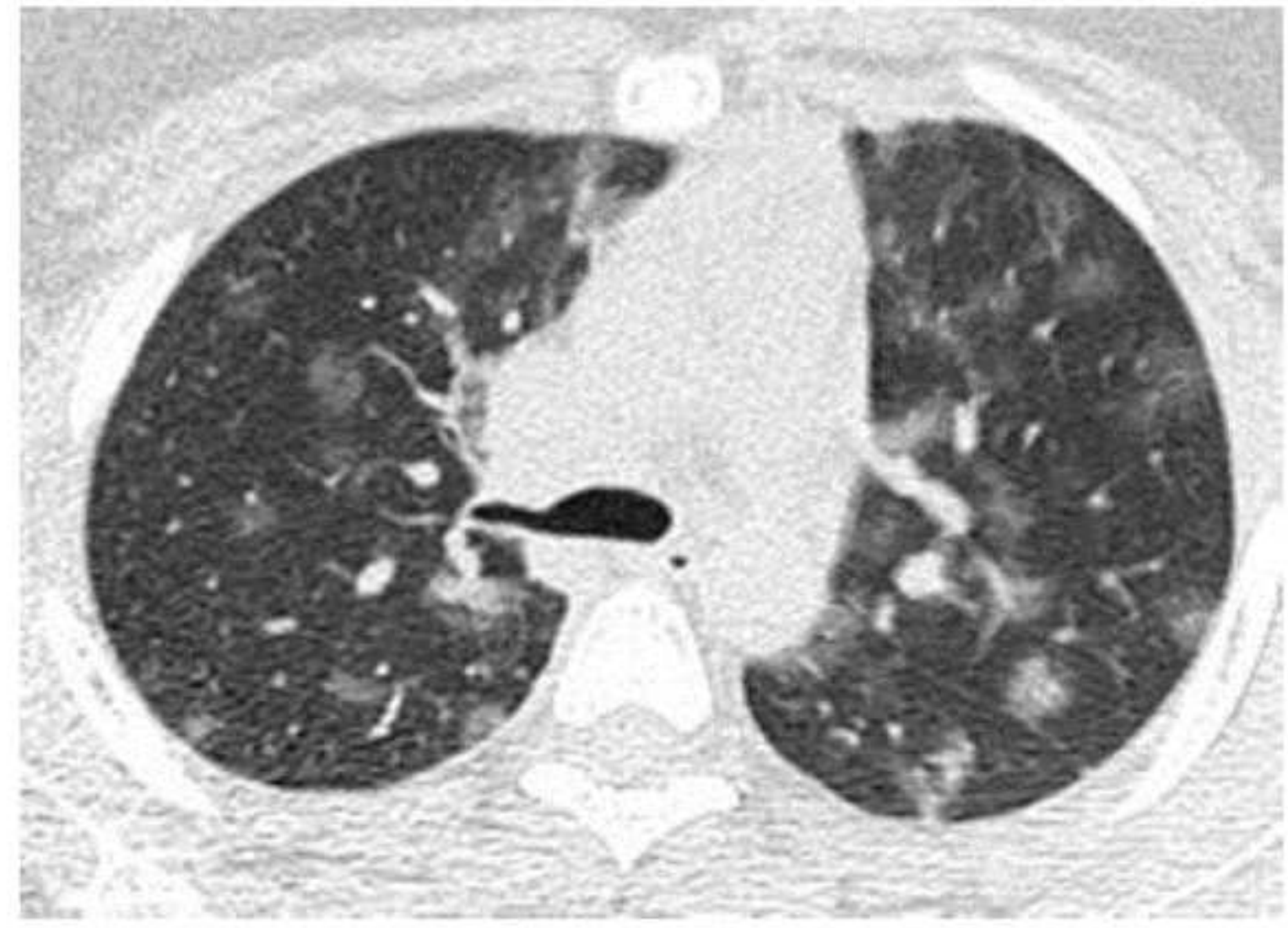

Figure 10

Ten-year-old boy, previously healthy, who presented with fever, dry cough, tachypnea and dyspnea that lasted for three days. Axial lung window CT image shows multifocal pneumonia with multiple groundglass nodules. 

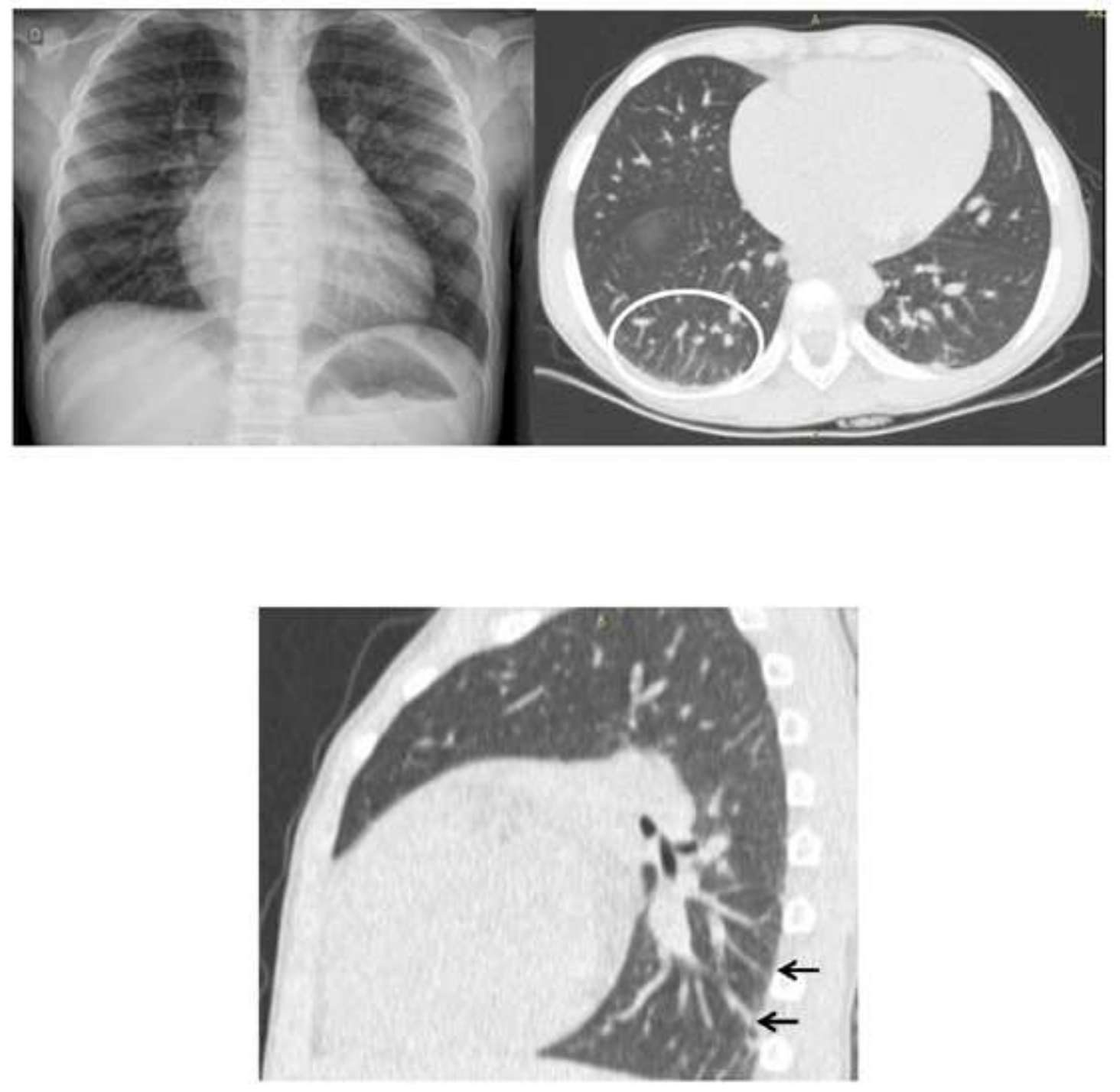

\section{Figure 11}

Ten-year-old girl, with sickle cell anemia presented with cervical pain that lasted one day. A. Frontal chest radiograph shows central peribronchial thickening and bilateral vascular engorgement. B. Axial CT image confirms vascular engorgement and shows parallel vascular tracts that reach the pleural surface (pulmonary comb sign inside the ellipse). C. The presence of peripheral vascular tracts that reach the pleura was corroborated at the sagittal reconstruction lung window CT image (black arrows).

\section{Supplementary Files}

This is a list of supplementary files associated with this preprint. Click to download.

- TableS1.png

- Figs1.png 